\title{
A 6-DOF Rehabilitation System for Upper Limbs "Robotherapist"and Other Rehabilitation Systems with High Safety
}

\author{
Junji Furusho and Ying Jin \\ Osaka University Japan
}

\section{Introduction}

The percentage of aged persons in society and their number are increasing, and their physical deterioration has become a social problem in many countries. Early detection of function deterioration and sufficient rehabilitation training are necessary, not only to decrease the numbers of aged who are bedridden or need nursing care, but also to enable the aged to take an active part in society. Movements of the upper limbs, such as eating and operating appliances are complicated, various and indispensable for daily activities. It therefore is important for the aged to exercise to keep their upper limb function. Moreover, there are many patients of paralysis caused by stroke. For example, in Japan more than two hundred and fifty thousand people have stroke every year, and many of them are paralyzed. The human brain is capable of an extraordinary degree of plasticity (selforganization), enabling learning, and leaving open the possibility for motor recovery (Janet \& Shepherd, 1998). Therefore, neuro-rehabilitation for stroke-patients is effective. Using apparatus that applies robotic technology and virtual reality makes new training methods and exercises in rehabilitation possible (Krebs, Volpe et al., 2000), (Burgar, Lum et al., 2000),(Charles, Krebs et al., 2005).

Feeding back the quantitative evaluations to the training by a computer can enhance the qualitative effect of training. Therefore, some rehabilitation systems using these technologies for upper limbs have been developed. However, most of them apply training within a twodimensional horizontal plane. Many movements, however, in daily activities need to move arms in a vertical direction. A system therefore that enables exercise in three-dimensions would seem to be more effective for such training. Although the MIME system (Burgar, Lum et al., 2000) using PUMA-560 by VA and Stanford Univ. can give training in threedimensions, the PUMA-560 is a robot originally developed for industrial use and may not be sufficiently safe to train the aged and/or disabled.

Furusho Laboratory of Osaka University have developed innovative rehabilitation supporting robots "Robotherapist", which is a 6-dofrehabilitation system for upper limbs including wrists in the 2-year NEDO Project (2004-2005). This system enables efficient rehabilitation trainings, which focuses on the harmonic movement of the whole upper limb. and Robotherapist was exhibited at the Prototype Robot Festival at the 2005 International 
Exposition held in Aichi Prefecture, Japan. "Robotherapist" Furusho Laboratory of Osaka Univ. and Osaka Electro-Communication Univ. are developing the rehabilitation software based on a physical therapy technique PNF using Robotherapist. In PNF, a therapist gives opposite force to patient in order to guide patient's hand in the desired direction. Then the patient resists the force from the therapist and knows which the desired direction is. We name this technique "Guidance Utilizing Reaction". In this chapter, we describe mechanism and software of Robotherapist and other rehabilitation systems using functional fluids with high safety.

Furusho Laboratory of Osaka University developed 2-D rehabilitation system for upper limbs "NIOH-1" using ER fluid actuators in 1997 (Furusho \& Sakaguchi, 1999). Robotherapist were developed on the basis of the technology of NIOH. Furusho Laboratory also developed 3-D rehabilitation system "EMUL". EMUL was developed through robotic and virtual reality technology in a 5-year NEDO (New-Energy and Industrial Technology Development Organization of Japanese Government) project and has performed well in clinical studies. Recently we have developed a upper-limb-rehabilitation system "PLEMO-P" using ER fluid brakes which could be used in facilities for elderly people and so on. Furusho Laboratory developed the passive-type force display system with two redundant brakes and a novel method is presented on the performance evaluation of the passive-type force display system with redundant brakes. We also have developed highly safe isokinetic exercise systems using only brakes with functional fluids (ER fluid or MR fluid). Because of rapid response of these fluids, such a machine has good responsibility and controllability. Meanwhile, Furusho Laboratory studied biped locomotion robots during the 1980s and the beginning of 1990s, and realized the human-like biped locomotion with kick action [Furusho \& Masubuchi, 1987], [Furusho \& Sano 1990]. On the basis of this biped locomotion technology and the technology about functional fluids, we developed the first intelligent prosthetic ankle. Moreover we are developing intelligent ankle-foot orthoses using MR (Magnetorheological) fluid in a 3-year NEDO project. Furusho Laboratory has developed the intelligently controllable AFO (I-AFO) which can control its ankle torque by using compact Magneto-rheological fluid (MRF) brakes. These systems are also introduced in this chapter.

\section{2-D Rehabilitation System "NIOH" 2.1 ER Actuaor}

\subsection{ER Actuaor}

ER fluid is a fluid whose rheological properties can be changed by applying an electrical field (Bossis, 2002). Fig. 1 shows the conceptual illustration of an ER fluid actuator. The ER actuator is composed of an ER clutch and its drive mechanism consisting of a motor and a reduction-gear-unit. The rotational speed of the motor is kept constant. The output torque of ER actuator is controlled by the applied electric field (Furusho, 2001), (Furusho \& Kikuchi, 2006). The input torque is transferred to the rotating cylindrical section of the output axis via the particle-type ER fluid filled in the rotating cylinder. Both the input axis cylinders and the output axis cylinder serve as electrodes, and output torque is controlled by the electric field applied between the electrodes. The output cylinder is made of aluminum alloy in order to reduce the moment of inertia of the output axis. An actuator using ER fluid is effective for human-coexistent mechatronics systems like rehabilitation systems for upper limbs. Fig. 2 shows a conceptual illustration of Human-Machine-Coexistent-Mechatronics (HMCM) 
System using ER Actuators. Merits of ER actuators in applications to HMCM system are as follows:

\section{A: From the Viewpoints of the Characteristics of Operation}

(1) Since ER actuators have good back-drivability, the operator can easily operate HMCM system from its end-effector.

(2) When HMCM system is driven by the operator from its end-effector, HMCM system can be moved quickly over the rotational speed of the input cylinder of the ER clutch.

B: From the Viewpoints of Performances in Force Display System

(1) Quick force response property originated from the low inertia property of ER actuator and the rapid response of ER fluid make the force presentation with high fidelity possible.

(2) Force display systems with large-force presentation ability can be realized safely.

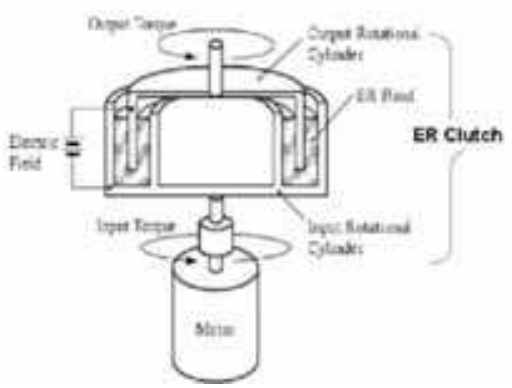

Fig. 1. Conceptual illustration of ER actuator

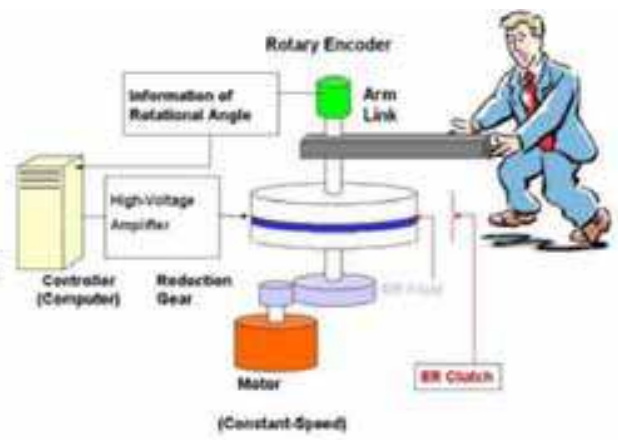

Fig. 2. Conceptual illustration of HumanMachine-Coexistent-Mechatronics (HMCM) Systems using ER actuators.

\subsection{Consideration about Safety}

A rehabilitation system for upper limbs which has large working area can be regarded as a kind of robots. In such a human-coexistent robot system where an operator must be in contact with or close to the robot, the safety-securing system is necessary in order that an operator can use the robot safely (ISO10218). In industrial robots, an operator cannot access a robot except for teaching in order to avoid hazardous conditions. Fig. 3 shows the structure of safety in human-coexistent robots.

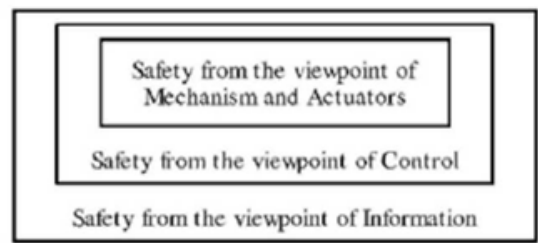

Safety from the viewpoint of Operation Condition

Fig. 3. Structure for securing safety in Human-Coexistent Robots. 
ER actuators have the following merits from the viewpoint of safety.

(1) The maximum driving speed of the output shaft of the ER actuator is restricted by the rotational speed of the input shaft of the ER clutch. Therefore, when the rotational speed of the input shaft is set slow, HMCM systems using ER actuators are safe for operators.

(2) The inertia of the output part can be made very small. So, in the case of unexpected accidents, the impact force caused by the inertia of the actuator can be reduced.

Since International Safety Standards for human-coexistent robots have not been established yet, we have no other choice but to use the ISO and domestic standards for machines working close to human beings (see Table 1). The developed rehabilitation system can assure these standards of Table 1 by the usage of ER actuators and the mechanical design as follows:

(1) The items (a) and (b) of Table 1 are satisfied by setting the rotational speed of the input cylinder slow.

(2) The item (c) is satisfied by using a 60-watt motor for the drive of the input rotational cylinder.

(3) Risk Reduction by Design (item (d)) is realized by mechanical limitation of each joint, mechanical gravity-compensation and the usage of ER actuators.

\begin{tabular}{|l|l|}
\hline (a) End-effector Speed is less than 0.25 [m/s] & ISO10218: Manipulating industrial robots--Safety \\
\hline (b) Low Energy Property & $\begin{array}{l}\text { ISO14121: Safety of machinery - Principles of risk } \\
\text { assessment }\end{array}$ \\
\hline (c) Actuator Power is less than 80 [W] & $\begin{array}{l}\text { JAPAN, JIS B 8433, 1983: General Code for Safety of } \\
\text { Industrial Robots }\end{array}$ \\
\hline (d) Risk Reduction by Design & $\begin{array}{l}\text { ISO12100: Safety of machinery - Basic concepts, } \\
\text { general principles for design }\end{array}$ \\
\hline
\end{tabular}

Table 1. International and domestic safety standards.

\subsection{Rehabilitation and Force Display Systems Using ER Fluids}

Furusho Lab. of Osaka University has been developing rehabilitation systems and force display systems using ER fluids since 1993 (Furusho, Wei et al., 1995).

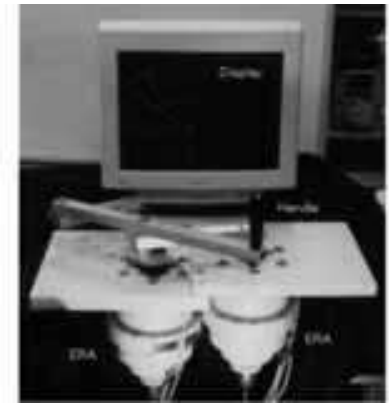

Fig. 4. Rehabilitation system "NIOH-1".

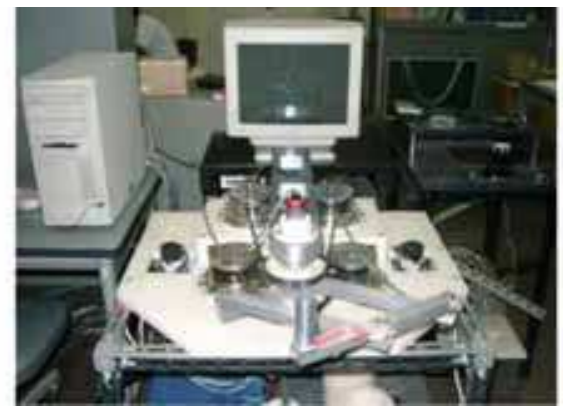

Fig. 5. Rehabilitation system "NIOH-2". 
Fig. 4 shows the 2-DOF rehabilitation systems "NIHO-1" using ER actuators (Furusho \& Sakaguchi, 1999). The rehabilitation training system was installed in a hospital for testing purpose. 13 patients volunteered to participate in several experiments for evaluation of upper limb's physical capability and for rehabilitation training (Sakaguchi, Furusho et al., 1999). The patients suffered from arm paralysis due to a damaged spinal cord or clogged brain artery. Fig. 5 shows the 2-DOF rehabilitation system "NIHO-2" using ER actuators (Ishikawa, 2000).

\section{6-DOF Rehabilitation System for Upper Limbs including Wrists "Robotherapist"}

\subsection{Introduction}

We have developed Robotherapist, which is a 6-DOF force display system for upper limbs including wrists (Furusho, Hu et al., 2006). The system can measure positions and postures of an operator's hand, and generate a large force sense including the wrist torque to the operator. This system enables efficient rehabilitation trainings, which focus on the harmonic movement of the whole upper limb. Robotherapist was exhibited at "The Prototype Robot Festival at the 2005 International Exposition held in Aichi Prefecture, Japan" (shown in Fig. 6).

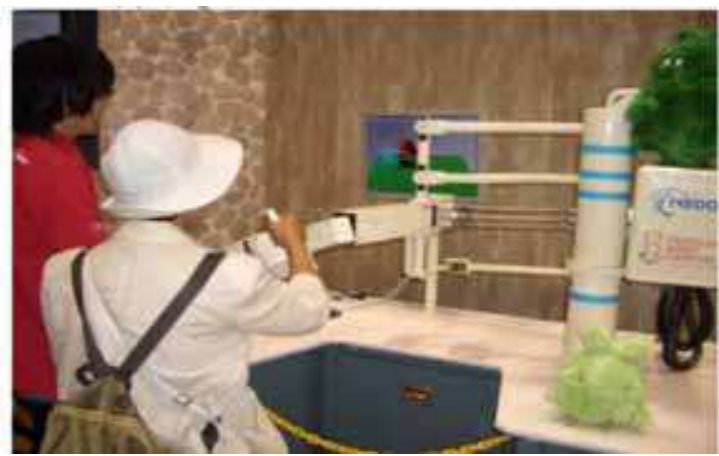

Fig. 6. Rehabilitation system "Robotherapist".

\subsection{Mechanism of Robotherapist}

A structure of Robotherapist can be divided into two mechanism groups: one is for positioning of an operating part (3-DOF) and another is for posturing of it (3-DOF). ER actuators drive all of 6-DOF.

\section{A: Mechanism for positioning of an operating part}

Fig. 7 shows the mechanism for the positioning. As seen from this figure, Robotherapist has 2-DOF for a horizontal rotation and 1-DOF for a vertical movement in arm parts. Actuators for arm motions are set on a base in order to reduce the inertia of the moving parts. Link2 is a parallel link mechanism. A counter-balance weight compensates a gravity-effect of these links in all posture.

B: Mechanism for posturing of an operating part

The mechanism for posturing has 3-DOF; that is, roll, pitch and yaw rotation. Generally, a heavy weight of an end-effecter impairs smooth acceleration of operation. Additionally, 
such a weight is very risky when the end-effecter collides with the operator. Therefore, the operating part was designed as light as possible. Actuators for the operating part are placed near Link1, and a torque of each actuator is transmitted to it by driving shafts and wirepulleys systems.

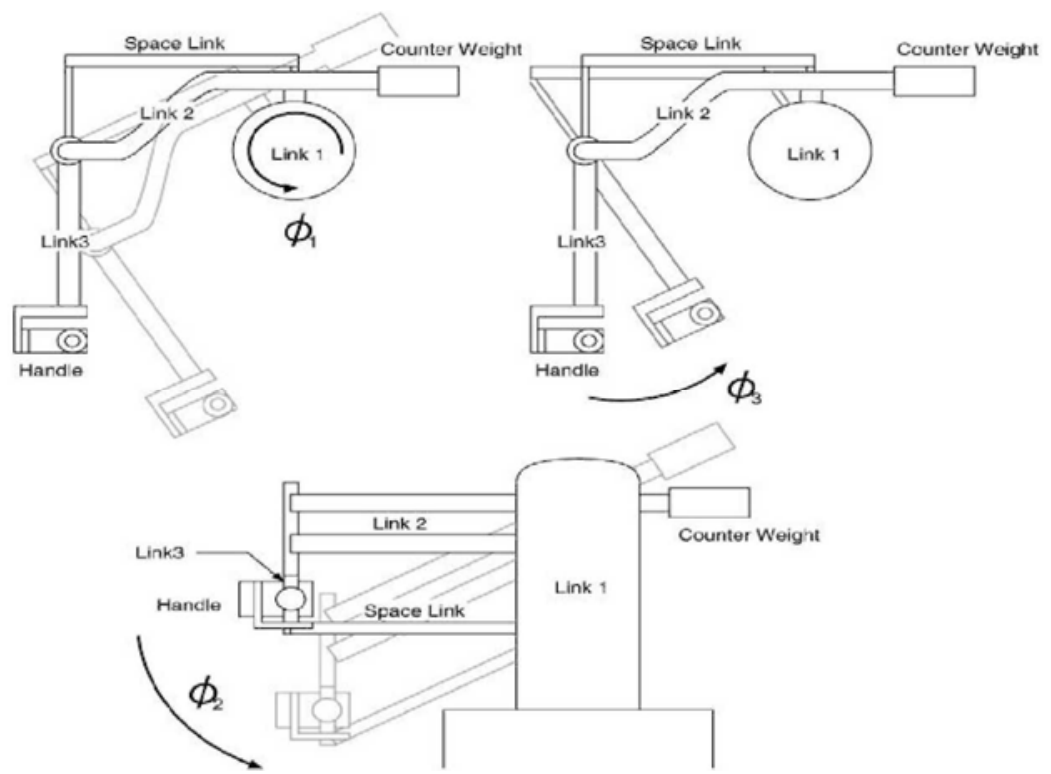

Fig. 7. Configuration of Robotherapist.

\subsection{Application Software of Robotherapist}

We have also developed application software of Robotherapist for upper limb rehabilitation that includes upper limb's harmonic movements. Important viewpoints for the rehabilitation training software are as follows:

(1) Many movements using the shoulder, the elbow, and the wrist harmonically are included.

(2) The sense of amusement is needed for long-term training.

(3) The recovery degree of upper limbs function can be evaluated properly.

The developed applications are the following four kinds.

\section{A: Water Supply (Shown in Fig. 8)}

The operator grasps a handgrip of a watering pod and gives water to the ground. The amount of the water, which comes out of the pod is calculated according as a tilt of the pod, and flower blooms gradually grow up according to the quantity of the given water. The goal of this game is making flower blooms on the whole ground. The system gives the operator a force depending on the tilt and the weight of residual water in the pod. The operator has to cooperate his shoulder, elbow, and wrist, in order to control the position and the tilt of the pod.

\section{B: Window Sweep (Shown in Fig. 9)}

At first whole area of the window is masked in white. The operator grasps a wiper and removes the white mask. If the mask is removed, a picture appears in the window. When 
the wiper is pressed on the window, the reaction force from the window is given to the operator. In order to remove the white mask efficiently, it is necessary to control not only the position but also the posture of the wiper. Therefore, the operator should move his shoulder, elbow, and wrist harmonically.

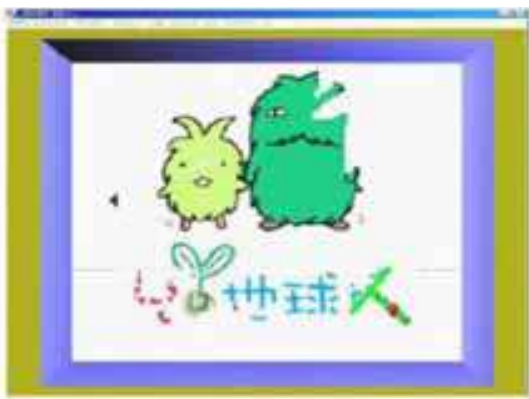

Fig. 8. Water supply.

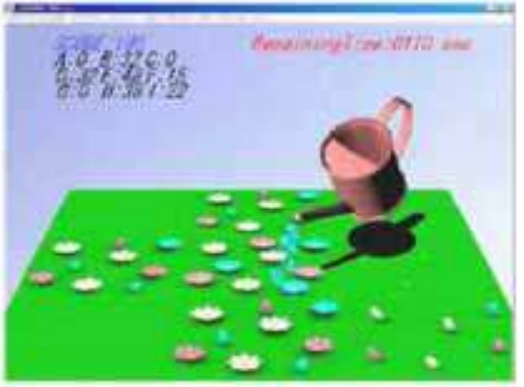

Fig. 9. Window sweep.

\subsection{Application Software of Robotherapist Based on PNF Techniques}

Furusho Laboratory of Osaka Univ. and Prof. Kunihiko Oda of Osaka ElectroCommunication Univ., Dept. of Physical Therapy are developing the evaluating software developed for the rehabilitation of patients suffered from cerebellum malfunction based on Proprioceptive Neuromuscular Facilitation (PNF) techniques (Furusho, Kikuchi, Oda et al., ICORR 2007).

\section{A: Rhythmic Stabilization}

Fig. 10 shows the image of Rhythmic Stabilization, and Fig. 11 shows the graphics of Rhythmic Stabilization. As shown in Fig. 10 and Fig. 11, a therapist gives each force from random directions quickly to the hand of a patient. And then the patient is instructed to maintain the position of his/her hand. In Rhythmic Stabilization, therapist want to know whether a patient can maintain the position of his/her hand, and how strong the force is, and which direction he is weak in.

\section{B: Finger Nose Finger (FNF)}

As shown in Fig. 12 and Fig. 13, a patient repeats the movement between therapist's finger and his/her nose under the expected orbit. In FNF, therapist would judge recovery degree of patient by his/her movement.

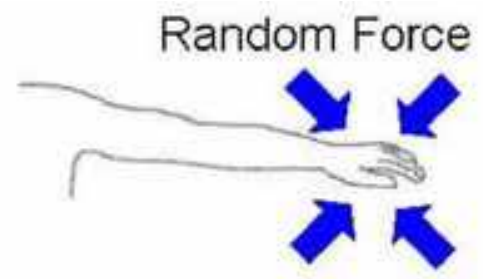

Fig. 10. Image of rhythmic stabilization.

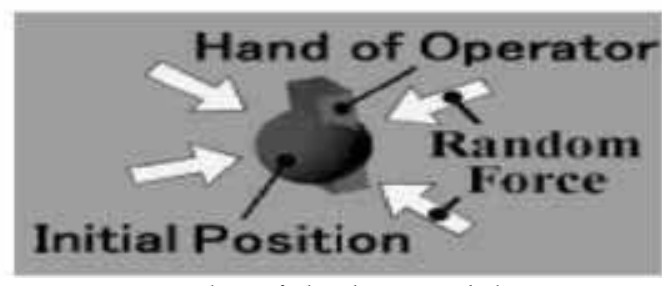

Fig. 11. Display of rhythmic stabilization. 

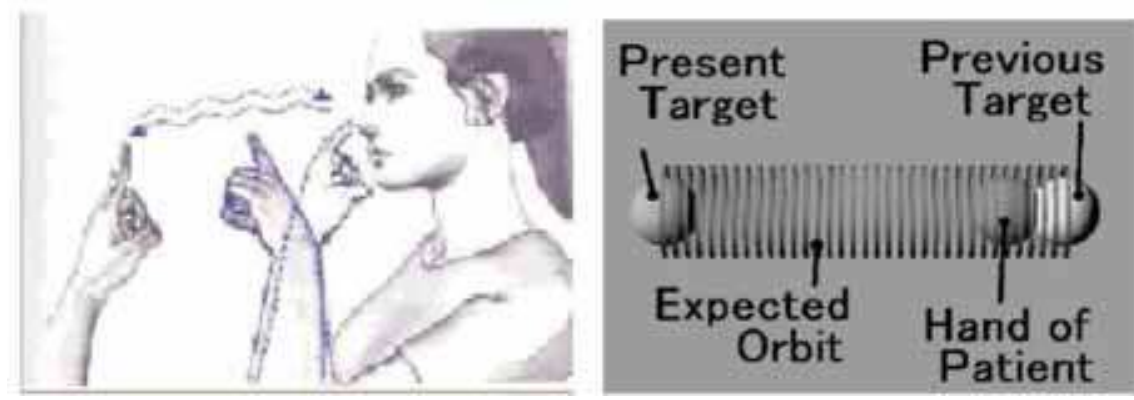

Fig. 12. Image of FNF.

Fig. 13. Display of finger nose finger.

\section{C: Arc Exercise with GUR}

In PNF, a therapist gives opposite force to patient in order to guide patient's hand in the desired direction. Then the patient resists the force from the therapist and knows which the desired direction is. We name this technique "Guidance Utilizing Reaction". As shown in Fig. 14, a patient extends his/her arm and moves his/her handle just on the arc orbit. When he moves it along the orbit, there is no force. Otherwise when the handle is away from the given orbit, the patient can sense force to his/her body.

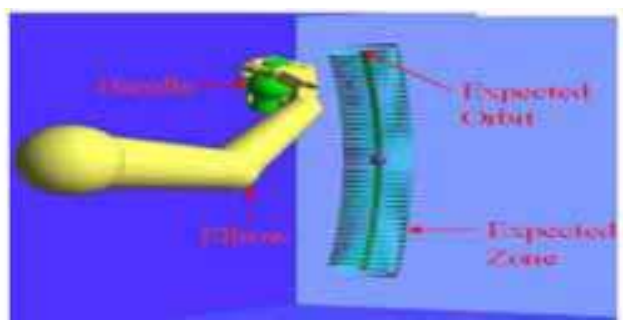

Fig. 14. Display of guidance utilizing reaction.

\subsection{Measurement of Reaching Movement with "Robotherapist" A: Stroke Rehabilitation}

The central paralysis is represented by hemiplegia of stroke. A qualitative abnormal exercise called synergy pattern in a recovery process appears to stroke survivors. If recovery progresses, stroke survivors return to a normal state. Synergy pattern is the movement which can move plural joints only along a certain constant pattern like flexor synergy or extensor synergy (Fig. 15 and Fig. 16). Therefore, when we evaluate a recovery state of upper limbs of stroke survivors, it is important to measure a movement pattern of the whole arm and to evaluate presence and degree of synergy pattern. 


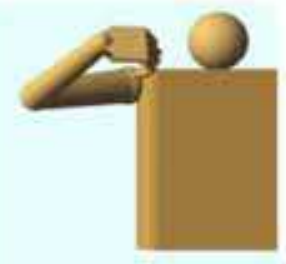

Fig. 15. Flexor synergy.

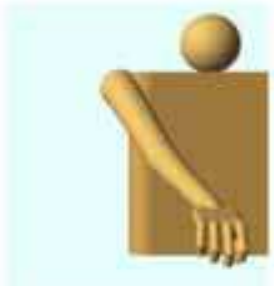

Fig. 16. Extensor synergy.

Many patients cannot move their hands actively as they like. Though they know a desired direction, they do not know how to move their hands in that direction. However, they can resist the force passively as they like. Therefore, we introduce physical therapy into application software.

We adopt techniques of Proprioceptive Neuromuscular Facilitation (PNF) in physical therapy. Techniques of PNF are used to place specific demands in order to secure a desired response (D.E.Voss, M.K.Ionta et al.). One of the techniques of PNF is the following: in order to guide a hand of a patient in one direction, a therapist adds force to the patient in the opposite direction, and the patient resists it (Fig. 17). Then his/her brain and body know how to move his/her hand in the correct direction. The force that the therapist adds depends on the maxim power of the patient. Utilizing the reaction against the force toward the opposite direction, the patient can tell correct movements to his/her brain and body. By repeating training with this technique, their brain learns the correct pattern of movements. We name this technique "Guidance Utilizing Reaction (GUR)". Then we introduce GUR technique to a rehabilitation robot system "Robotherapist" and its software.

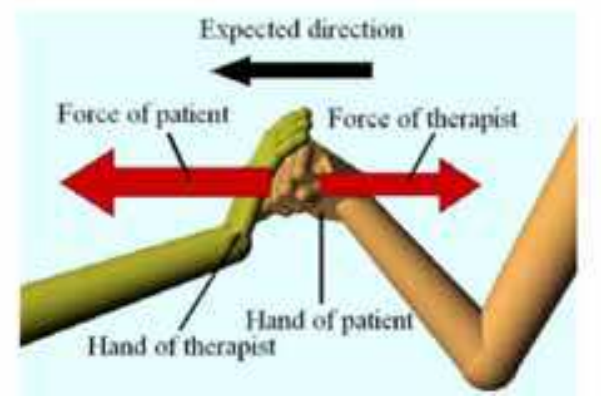

Fig. 17. Guidance Utilizing Reaction (GUR).

\section{B: Measurement Experiment of Reaching Movement}

We experimented on a measurement of reaching movement with Robotherapist. Additionally, we made a model of movement peculiar to stroke survivors and a model of movement of healthy people.

(1) Way of Experiment

Subjects are eight students who are healthy people and one therapist. Eight students did natural reaching movement of the right hand, and one therapist did reaching movement of the right hand which simulated stroke survivors. An appearance in an experiment is shown 
in Fig. 18. A screen such as Fig. 19 was displayed in the experiment. Subjects moved the handle to front and back along the aim orbit. We measured and recorded the position and posture of the handle and the wrist angle and estimated the elbow position.

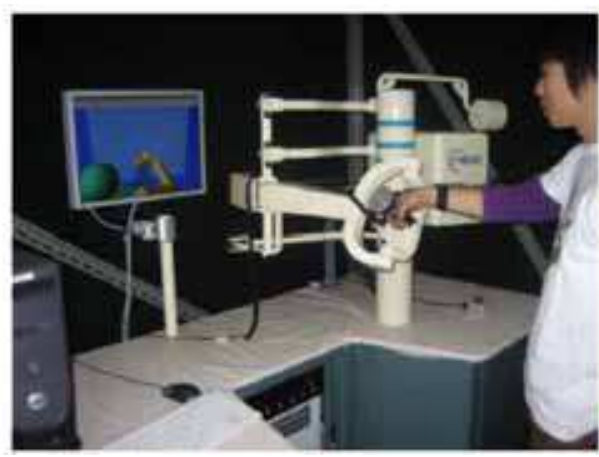

Fig. 18. Appearance in experiment.

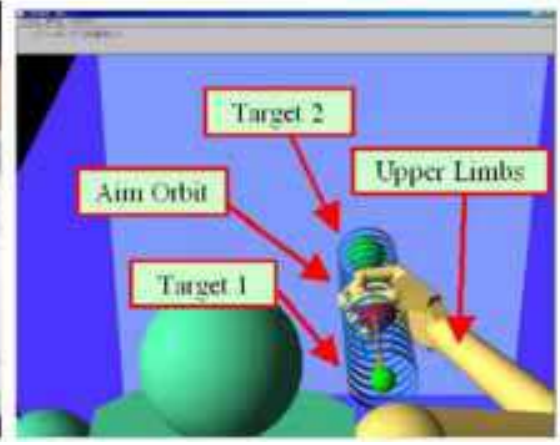

Fig. 19. Screen in experiment.

\section{C:Application Software for Reaching Training}

In this section, we describe application software for reaching training that we developed. A trainer operates Robotherapist while looking at a screen. As a reaching training menu, there are two modes to guide the position of the handle part and to improve the posture of the handle part.

(1) Guide Mode of Handle Part

Based on the method of GUR, Robotherapist presents force sense of the opposite direction to the expected direction to a trainer. The expected direction is the direction to the target. When the position of the handle part leaves aim orbit more than a certain distance, a message is displayed on the screen and he is warned by a sound. Simultaneously, the expected direction changes to a direction returning to the aim orbit.

(2) Improvement Mode of Upper Limbs

We intend for a patient who can extend his arm along the aim orbit. In this mode, Robotherapist doesn't present force sense to guide the position of the handle part. When he extends his arm, a wrist angle, a direction of palm and a position of an elbow are measured. If reaching movement is abnormal, he is warned by a message and a sound. We use the model of stroke survivors and that of healthy people in a foregoing section for abnormal search. When his reaching movement approaches in the model of stroke survivors, we judge that it is abnormal. If his reaching movement is judged abnormal about dorsal flexion, palmar flexion, supination and pronation, Robotherapist presents force sense. 


\section{A 3-D Rehabilitation System for Upper Limbs Developed in a 5-year NEDO Project "EMUL"}

\subsection{Introduction}

The percentage of aged persons in society and their number are increasing, and their physical deterioration has become a social problem in many countries. Early detection of function deterioration and sufficient rehabilitation training are necessary, not only to decrease the numbers of aged who are bedridden or need nursing care, but also to enable the aged to take an active part in society. This research has been conducted as a part of the NEDO (New Energy and Industrial Technology Development Organization) 5-year Project, "Rehabilitation System for the Upper Limbs and Lower Limbs" since 1999. Furusho Laboratory of Osaka University and Asahi-kasei Group developed a 3-D rehabilitation system for upper limbs "EMUL". Hyogo Medical College took part in the project in the final year.

\subsection{3-DOF Rehabilitation Training System}

We have developed a 3-D rehabilitation system that has a performance suitable for rehabilitation for upper limbs and can display force senses in three-dimensional space (Furusho, Koyanagi, Imada et al., 2005), (Furusho, Koyanagi, Kataoka et al., 2005).

Fig. 20 shows the whole rehabilitation system. The maximum output torque of the ER actuator is about 3.0 [Nm]. As shown in Fig. 20, exercise machine. The major targets in this study are hemiplegic patients who were paralyzed by stroke. The training in general includes physical therapeutic exercises, such as passive and active exercises, and occupational therapeutic exercise like eating movement. EMUL has the following specifications.

(1) EMUL has 2 DOF for horizontal rotation and 1 DOF for vertical rotation.

(2) The length of each link is $0.45[\mathrm{~m}]$ and the height of the whole machine is about $1[\mathrm{~m}]$.

(3) All the actuators are set on the base of EMUL.

(4) The vertical rotation part adopts a parallel link mechanism. This makes the gravityeffect compensation by counterbalance-weight in all posture possible.

(5) The 3rd link is driven by spatial parallel link mechanism instead of belt-pulley and gear transmission system.

(6) The motion range is about $0.90[\mathrm{~m}](\mathrm{W}) * 0.54[\mathrm{~m}](\mathrm{D}) * 0.50[\mathrm{~m}](\mathrm{H})$.

(7) The generative force at the end-effector is about $23[\mathrm{~N}]$ in the horizontal plane and about $60[\mathrm{~N}]$ in the vertical direction.

\subsection{Software for Training}

We show several examples of the training software.

\section{A: Picture-Mask Erasing}

As shown in Fig. 21, a semitransparent mask of a picture of $0.40[\mathrm{~m}]{ }^{*} 0.40[\mathrm{~m}]$ is erased by a virtual eraser which is operated by a patient. The patient can sense a reaction force from the picture surface through the gripper of 3-D rehabilitation system. This software has the effect of improvement about the dexterity and the movable range of limbs.

B: Virtual Maze \& Virtual Hockey

Fig. 22 shows a virtual maze of $0.40[\mathrm{~m}] * 0.30[\mathrm{~m}]$. This software has the effect of improvement about the dexterity and the movable range of limbs. Fig. 23 shows a virtual 
hockey game with impact-force-sense. Virtual hockey has the training effect about dexterity and agility.

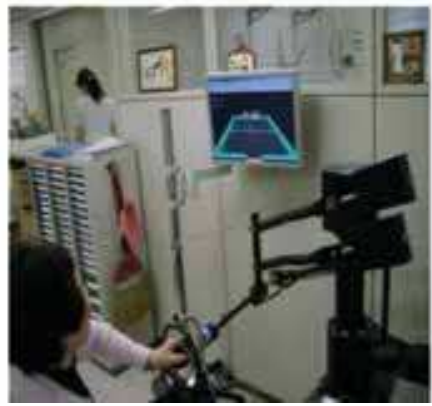

Fig. 20. Rehabilitation system "EMUL".

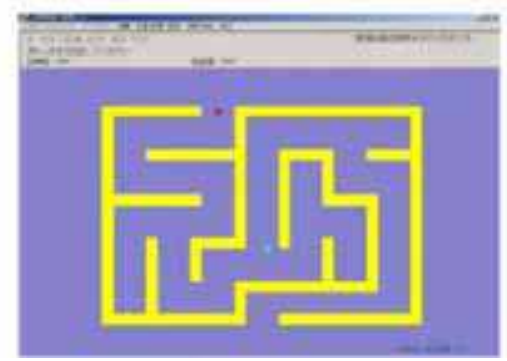

Fig. 22. Virtual maze.

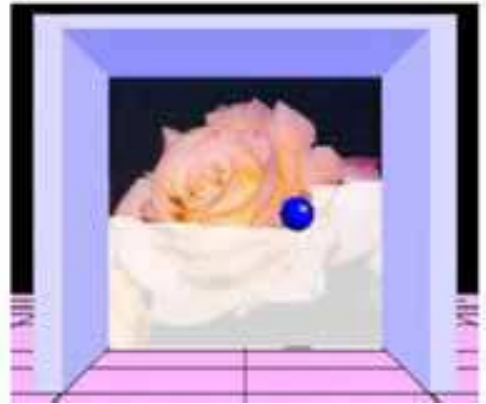

Fig. 21. Picture-mask erasing.

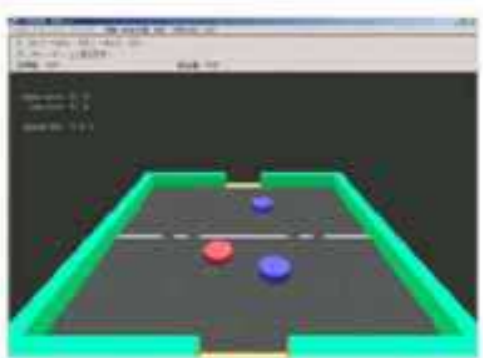

Fig. 23. Virtual hockey.

\subsection{Clinical Evaluation of EMUL}

We conducted clinical testing for six stroke patients shown in Table 2. Each patient underwent 40 minutes of robotic therapy three times a week for six weeks. No patient showed severe cognitive impairment. None of the subjects was engaged in conventional occupational or physical therapy. Fig. 24 shows the shape of movable range in PictureMask-Erasing training of the female patient of 60 years old. As seen from this figure, the movable volume is expanded by the training.

\begin{tabular}{llll}
\hline Age & Gender & Location of Cereberal Vascular Accident (CVA) & Months since CVA \\
\hline 60 & Female & Right thalamus $\cdot$ Infract & 45 months \\
67 & Male & Right corona radiata $\cdot$ Infract & 18 months \\
20 & Male & Left parietal cortex $\cdot$ hemorrhage & 39 months \\
62 & Female & Left frontal cortex $\cdot$ Infract & 94 months \\
67 & Female & Right corona radiata $\cdot$ Infract & 110 months \\
57 & Female & Left frontal cortex $\cdot$ Infract & 40 months \\
& & &
\end{tabular}

Table 2. Cases

Professor Kazuhisa Domen's group of Hyogo Medical College and professor Junji Furusho's 
group of Osaka University reported the clinical evaluation results shown in Table 3 in the Japanese Journal of Rehabilitation Medicine (Miyakoshi, Domen et al., 2006). As seen from these tables, the training using EMUL improves the motion ability of the patients.

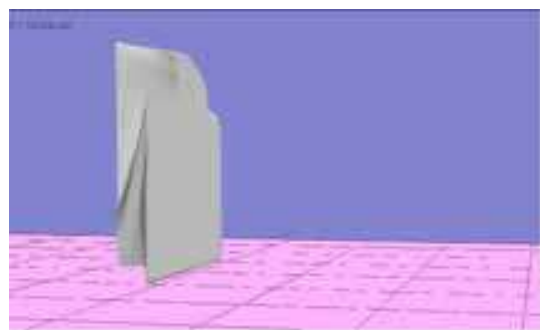

(a) Result of the first training

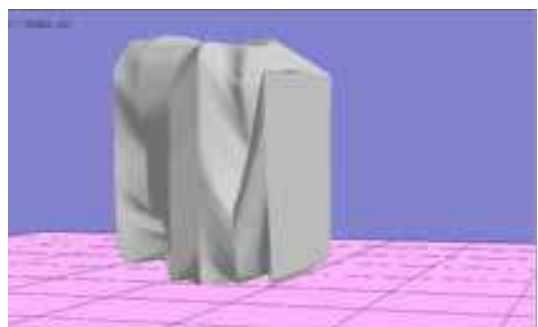

(b) Result of the final training.

Fig. 24. Picture-mask erasing

\begin{tabular}{lccc}
\hline Methods of Assessment (Range of Points) & $\begin{array}{c}\text { Pre-treatment } \\
\text { mean } \pm \text { SD }\end{array}$ & $\begin{array}{c}\text { Post-treatment } \\
\text { mean } \pm \text { SD }\end{array}$ & $p$ \\
\hline FMA $^{*}$; total $(0 \sim 66)$ & $45.2 \pm 11.3$ & $51.2 \pm 11.7$ & 0.0273 \\
FMA ; shoulder/elbow/forearm $\quad(0 \sim 36)$ & $25.8 \pm 7.5$ & $28.3 \pm 6.1$ & 0.0412 \\
FMA ; wrist $(0 \sim 10)$ & $5.2 \pm 2.6$ & $6.2 \pm 4.2$ & 0.2356 \\
FMA ; finger $(0 \sim 14)$ & $11.2 \pm 3.1$ & $12.7 \pm 1.2$ & 0.2763 \\
FMA ; speed/coordination $(0 \sim 6)$ & $3.0 \pm 1.9$ & $4.0 \pm 1.5$ & 0.0633 \\
Motricity index (0 100) & $77.7 \pm 7.6$ & $85.8 \pm 10.0$ & 0.0679 \\
Grasping Power [N] & $78.4 \pm 35.3$ & $105.8 \pm 38.2$ & 0.0782 \\
12-Stages -Grade by Ueda** $(0 \sim 12)$ & $6.2 \pm 1.8$ & $7.7 \pm 2.3$ & 0.0412 \\
\hline
\end{tabular}

*FMA: Fugl-Meyer Assessment (Fugl-Meyer . et al., 1975)

**Ueda Grade: 0 (Brunnstrom Stage I); 1,2(Brunnstrom Stage II); 3-6(Brunnstrom Stage III);

7,8(Brunnstrom Stage IV); 9-11(Brunnstrom Stage V); 12(Brunnstrom Stage VI)

Table 3. Results of Assessment at Pre-treatment and Post-treatment $(n=6)$ (This table is a revised version of the reference paer by Miyakoshi, Domen et al., 2006.)

\subsection{Development of Evaluation System of the Motor Function for Upper Limbs using 3-D Rehabilitation Robot "EMUL" and Brain Function Imaging Method "NIRS"}

In recent years, the rehabilitation system using robot and virtual reality is expected to quantify the effect of rehabilitative training. In this section, we describe about the development of evaluation system of motor function for upper limbs using 3D rehabilitation Robot "EMUL" and brain function imaging method "NIRS". This makes the evaluation system more quantitative. This work is joint research between Osaka University and Morinomiya Hospital.

\section{A: NIRS}

NIRS is a method of the brain function mapping utilizing the near-infrared lay (wavelength from $700 \mathrm{~nm}$ to $2500 \mathrm{~nm}$ ), which has high transmission to body issues. By irradiating the near-infrared lays to the body issues and observing that transmitted lay, cerebral cortical changes in hemoglobin can be detected. NIRS has the advantage that it can observe the 
cortical activities during dynamic movements against the other brain mapping methods: fMRI, PET, MEG and so on.

\section{B: Clinical Evaluation}

In order to evaluate the relationship between training using EMUL and cortical activation during operation the robot, we prepare "Eight Vertex Reaching Program" (shown in Fig. 25) as training / evaluation software of EMUL. Fig. 26 shows the software of "Eight Vertex Reaching Program". In this program, subjects reach each vertex of virtual cube on the display of EMUL. subject's hand is guided to a starting vertex by the robot arm of EMUL. During these training, the motion data of subject's hand are observed with EMUL and the cortical activation data are observed with NIRS.The subjects participating in this experiment are 7 healthy adults. They have not excised with rehabilitation robots before. This measurement experimentation are performed at the Morinomiya hospital. Fig. 27 shows the experimental scene.

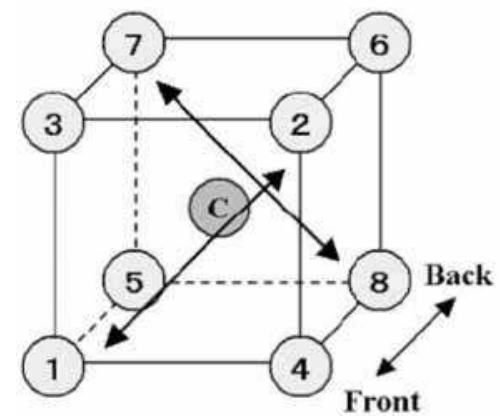

Fig. 25. Eight vertex reaching program

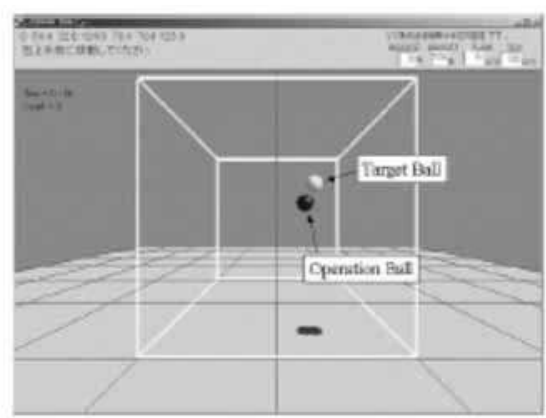

Fig. 26. Eight vertex reaching program (software)

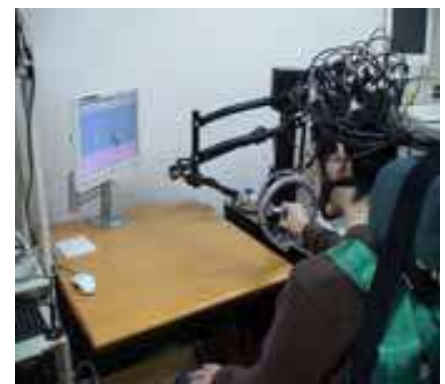

Fig. 27. Experimental scene using EMUL \& NIRS.

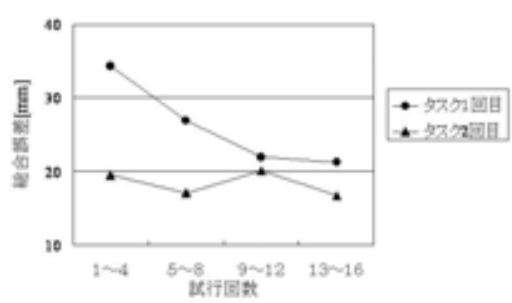

Fig. 28. Total Error

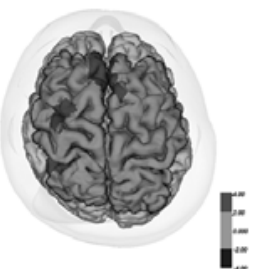

Fig. 29. Cortical activation data.

One of the motion data , for example, "Total Error", which is the distance between the target ball and the operation ball, is shown in Fig. 28. This index means the accuracy of tracking. Fig. 29 shows one of the cortical activation data of NIRS. The data are the average of all subjects' Oxygenated-Hemoglobin changes from 0 [sec] to 12 [sec] after beginning of the program. The area becomes the more red, it shows that area are more activated comparing with the condition during the rest time. The prefrontal cortex area and the premotor cortex 
area had activated in the task-Al, however, that performance had calmed down after task-B. When comparing the data of task- $\mathrm{Al}$ and task-A2, there are significant differences at the left premotor cortex area and the medial prefrontal cortex area.

\section{Quasi-3-DOF rehabilitation System "PLEMO"}

\subsection{Introduction}

In general, therapists make the rehabilitation program based on an inspection and a measurement of each patient. However, it is difficult to adopt appropriate rehabilitation programs for all patients, because the evaluation method is based on experiences of each therapist. Recently, Evidence Based Medicine (EBM) is required strongly in the field of rehabilitation. Therefore robot-aided rehabilitation is expected to quantify the effect of rehabilitative activities. We developed 3-D rehabilitation system for upper limb "EMUL" and 6-DOF rehabilitation system "Robotherapist", and conducted clinical test with several kinds of video game. EMUL and Robotherapist adopted to use ER actuators and clutch mechanism for its actuation part. This mechanism makes these systems so safe and backdrivable. However, they have disadvantages in cost or ease of maintenance, because this system became enlarged to realize the force-feedback in large 3-D space. A system which is more compact and better for maintenance should be required for practical use. To meet the demands above, we developed new haptic device which has 2-DOF force-feedback function in working plane but its working plane can be adjusted the inclination. We named this system "Quasi-3-DOF Rehabilitation System for Upper Limbs" or "PLEMO" (shown in Fig. 30) (Kikuchi, Furusho, Jin et al., CME2007). PLEMO was developed to realize quantitative evaluation of the rehabilitation training for patients with spasticity after stroke. In this section, we describe the mechanism of PLEMO and its software for upper limb rehabilitation.

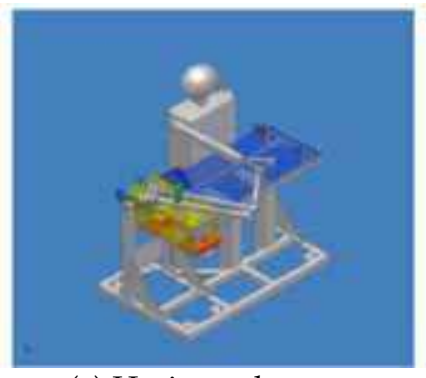

(a) Horizontal state

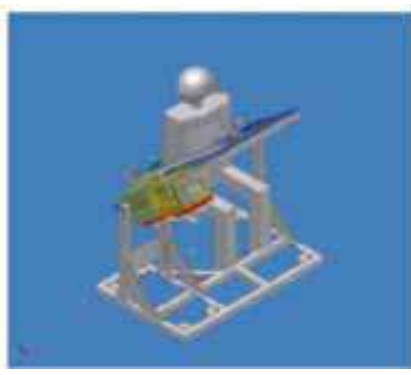

(b) Slanted state

Fig. 30. Quasi-3-DOF rehabilitation system "PLEMO".

\subsection{ER Brake}

Using ER fluid as working fluid, we construct electrically controllable brake (ER brake) with high-performance (good rapidity and repeatability of brake torque) (Kikuchi, Furusho et al., 2003). We use this brake for the force generators of new rehabilitation system (forcefeedback system). Fig. 31 shows the sectional view and appearance of the brake. As shown in the left drawing of Fig. 31, this brake consists of multi-layered disks. ER fluid is filled between the 
rotor-disks and stator-disks. As a result, six layers of ER fluid generate brake torque with the change of the fluid. Piston mechanism works for the prevention of liquid spill with thenexpansion of the fluid. We can control the brake torque form $0.1[\mathrm{Nm}]$ to $4.0[\mathrm{Nm}]$ with applied electric field from $0.0[\mathrm{kV} / \mathrm{mm}]$ to $3.0[\mathrm{kV} / \mathrm{mm}]$. Additionally, response time of torque is several milliseconds.
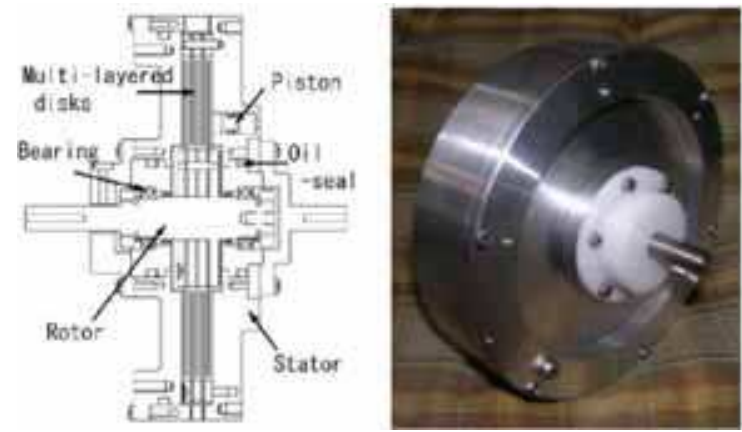

Fig. 31. ER Brake: sectional view (left) and picture (right).

Fig. 32 shows a passive force display using ER brakes (IEEE Virtual Reality 2001) in previous research (Furusho, Sakaguchi et al., 2002). In the research, we established control methods with a passive force display system on 2-D space. On the basis of this technology, we developed basic structure and control method of PLEMO.

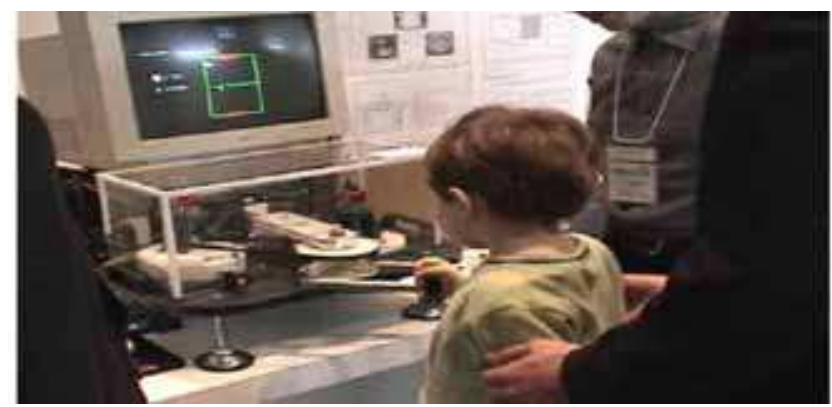

Fig. 32. Passive force display using ER brakes (PLEMO-P-Prototype).

\subsection{Quasi-3-DOF Rehabilitation System for Upper Limbs, "PLEMO"}

Based on the technology of PLEMO-P-Prototype, we developed Ouasi-3D Rehabilitation System PLEMO-P series, PLEMO-P1,PLEMO-P2,PLEMO-P3 and so on. Fig. 33 shows the rehabilitation system of PLEMO-P3 (Furusho., Ozaw et al., 2009). The angle of working plane can be adjusted according to the rehabilitation program. We named this system "Quasi-3-DOF Rehabilitation System for Upper Limb" or "PLEMO". PLEMO is a combination of "pleasant" and "motivation". This word includes our hope that this system gives patents a pleasant experience of recovery and motivation for rehabilitation trainings. This system is safe for human because it use only brakes. Force control unit consist of the two ER brakes and the brake torque generates output-force on a handle by a parallel 
linkage. Working area of PLEMO is $0.6[\mathrm{~m}](\mathrm{W})$ * $0.5[\mathrm{~m}](\mathrm{D})$. Adjustable angle of the inclination is from -30 to 90 degree. Plemo-Pl realizes from vertical training to horizontal training by only one system. Total size of the system is $1.0[\mathrm{~m}](\mathrm{W}){ }^{*} 0.6[\mathrm{~m}](\mathrm{D}){ }^{*} 0.7[\mathrm{~m}](\mathrm{H})$, except for the display. This is similar to the size of general desks. Not to use any actuator contributes to make this system more compact, simple, and reasonable for cost.

We developed new sensing device for detecting abnormal symptoms and aim to build an appropriate evaluation system for stroke patients with information of abnormal symptoms. Fig. 34 shows mechanisms of our former and current handle.

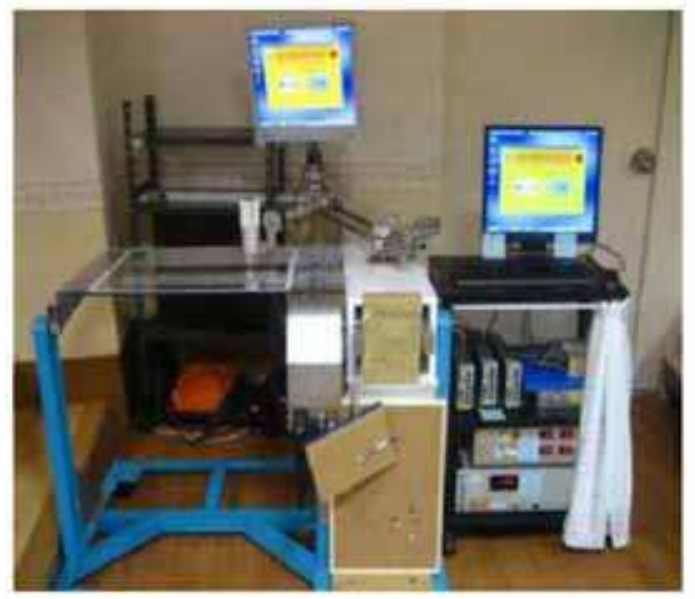

Fig. 33. PLEMO-P3

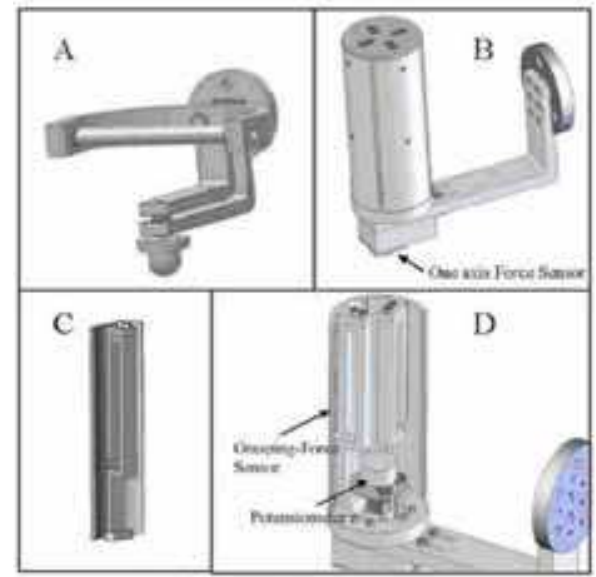

Fig. 34. Sensor grip device: (A) Former handle (passive gimbal), (B) Current handle (sensor grip), (C) A part of grip force sensor, (D) inner mechanism of the grip device 


\subsection{Software of PLEMO}

We develop a rehabilitation software shown in Fig. 35. This is a tracking test program. An operator grips the handle and moves it to track a target ball. The position of operating handle is displayed as red sphere. The target ball is moving along the target track. White zone in this figure means smooth area without any force-feedback. Blue zone means sticky area; operator feels virtual force like moving his hand in the viscous fluid. It is easy to change kinds of the virtual forces and its area. Data of position, velocity and operating force are saved in the output files and we can evaluate accuracy of poison and velocity, range of motion, cognitive faculty and so on. We should make decision of the training protocol and evaluating method depending on the symptom of patient individually.

We have developed an evaluation program for reaching/pulling movements (Shown in Fig. 36(A); this software is similar to conventional 'reaching/pulling training'. Moreover, symptoms of patient's synergic movements can be detected during training. In this program, a patient is instructed to the position of target point (sphere shape in this figure) with each numbers in the monitor. The position of the hand is shown as the small white dot, which is moved depending on the movement of the end-effecter. The task starts when a patient operates his/her hand to the start position displayed as the yellow small dot in Fig. 36. The subjects are six stroke patients with different Brunnstrom stages and twenty-seven healthy volunteers. PLEMO was used to measure the moving features of the healthy subjects and stroke patients ( Brunnstrom stage 3,4,5). The experimental results show big difference between the stroke patients and the healthy people. We construed the difference is based on the synergy movement of stroke. Now, we are trying to make an appropriate evaluation system of stroke patients based on these differences.

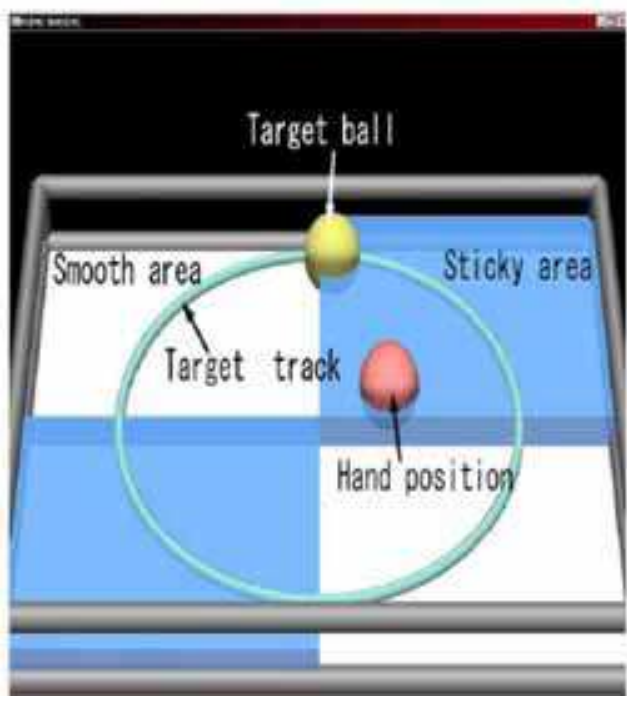

Fig. 35. View of tracking test (software of PLEMO-P1,PLEMO-P2,PLEMO-P3)

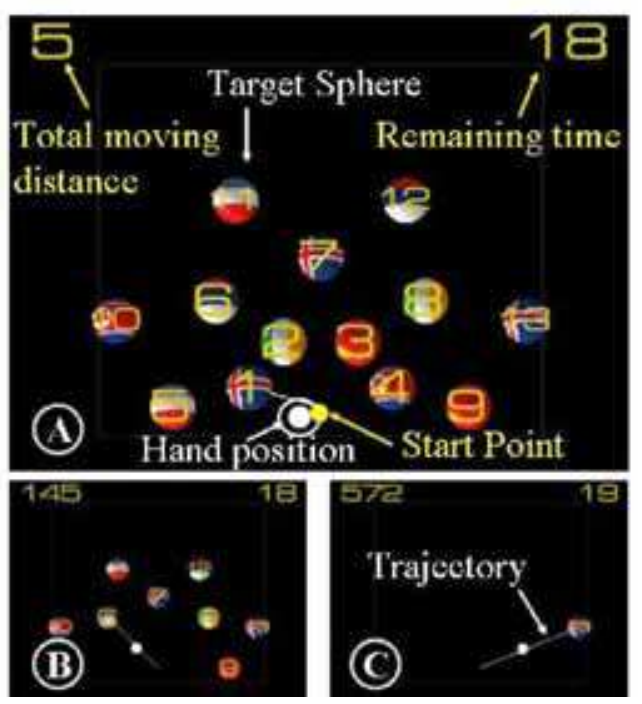

Fig. 36. Reaching application software (PLEMO-P3) 


\subsection{Hybrid-PLEMO (Jin , Kikuchi et al.,2008)}

"Hybrid-PLEMO" is one type of PLEMO, which can switch active type and passive type (see Fig. 37). To generate haptic force on the end-effector, we use double-shaft ER Brake (shown in Fig. 38) as ER clutch. Fig. 39 shows the mechanism of Input parts of actuator box. In order to transmit forces from the Er clutches to the end-effector, we take direct-drive mechanism by using parallel linkage mechanism(shown in Fig. 40 )

We suggest two types of reaching program with Hybrid-PLEMO system (shown in Fig. 41). search target trajectory with only force information and trace it. In active mode, PLEMO system generates outgoing- vector force of $5 \mathrm{~N}$ from target trajectory. On the other hand, in passive mode, the system generates a distribution of resistant force $(0 \mathrm{~N}$ or $3 \mathrm{~N}$ or $5 \mathrm{~N})$. The nearer to the target the hand position is, the stronger the resistance is. The start position was same $(X=0 \mathrm{~cm})$ in every experiment. The target changes its $X$ position $(X=-20,-10,0,10$, $20 \mathrm{~cm}$ ) in a random manner. In order to evaluate simply the effect of force information, we hide any visual information on display. Fig. 42 show experimental results of same target position $(X=10 \mathrm{~cm})$ with active/passive mode. An operator is healthy person. Broken lines show the target trajectory, and black dots show the starting position of the handle. As shown in the left side of Fig. 42, operator can recognize the target position smoothly with active-type force guidance. On the other hand, as shown in the right side of Fig. 42, it took more time to recognize the target position with passive-type force guidance than active mode. The reason of this delay is thought that, in passive mode, the operator needs more time to understand the distribution of force field with his own motion, and recognize correct direction toward the target. In future works, we must clarify effects and roles of active / passive force feedback for human's sense, motion and rehabilitation.

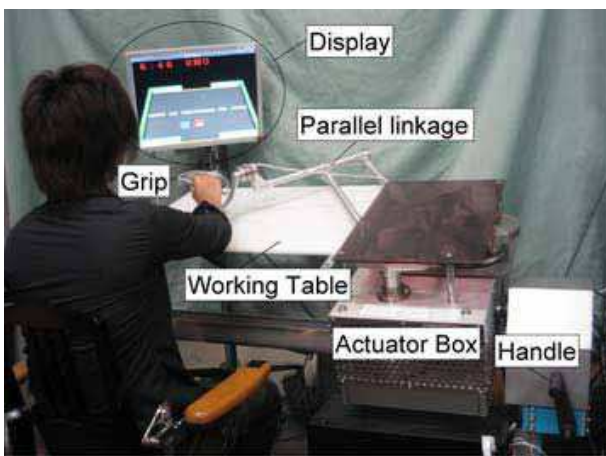

Fig. 37. Hybrid-PLEMO

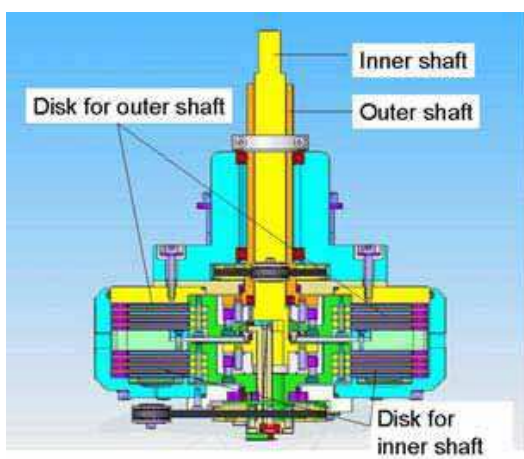

Fig. 38. Double-shaft ER brake/clutch 


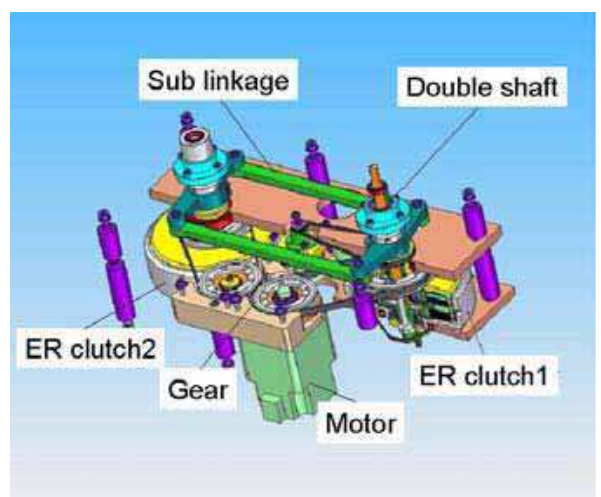

Fig. 39. Input parts of actuator box

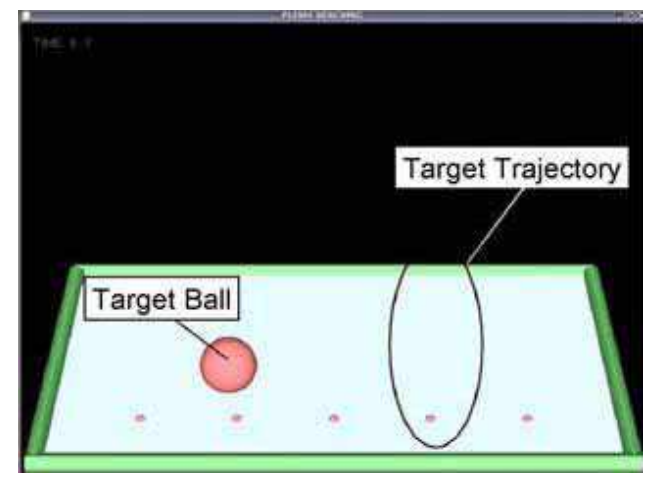

Fig. 41. Application "Reaching"

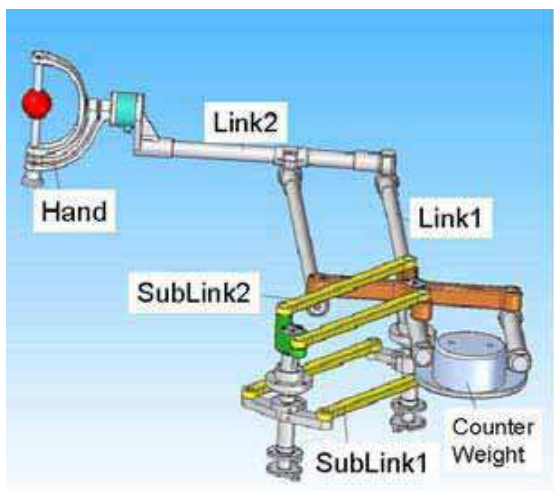

Fig. 40. Parallel linkage mechanism

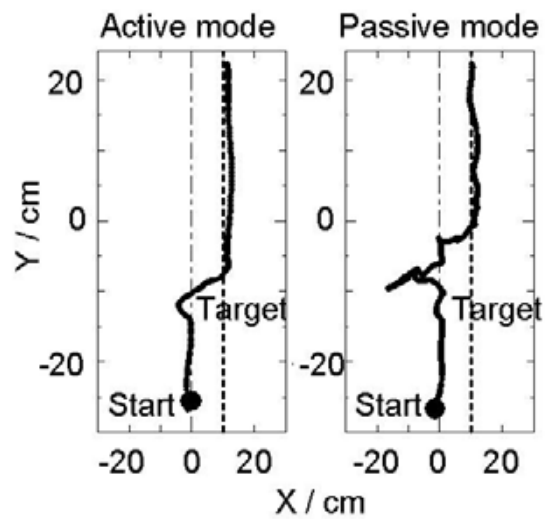

Fig. 42. Experimental Results

\section{2-DOF Passive-type force Display and Rehabilitation System with Redundant Brakes (Jin, Kikuchi et al., 2009)}

\subsection{Introduction}

We have developed "Hybrid-PLEMO" system with another concept for safety. It has only 2DOF force feedback function on working plane for downsizing and low-cost, its working plane can be adjusted the inclination, and it can be switched between active type and passive type.

However, there are some directions and link positions that are difficult to display the force when Hybrid-PLEMO works at passive type. To solve this problem, Davis and Book (Davis \& Book, 1997) studied a passive manipulator with a redundant actuation scheme by using redundant electromagnetic brakes. However, the controllability and response time of electromagnetic brakes and power brakes are not good for using force display system. The various methodologies for performance evaluation of haptic device have been introduced through diverse researches (Lawrence \& Chape, 1994 and Jinung \& Kwon, 2002). However, there are no succinct performance evaluation methods that are common to any haptic 
passive device with redundant brakes. In our study, a novel method is presented for performance evaluation of a passive-type force display system with redundant brakes. Using this method, we evaluate the performance of a 2-DOF passive-type force display system with and without redundant brakes. Experimental results show that it is good to add redundant brakes to the passive-type force display and rehabilitation system.

\subsection{2-DOF Passive-type force Display \& Rehabilitation System with Redundant Brakes}

Fig. 43 shows the force display system with redundant couple of brakes (Koyanagi, Morita et al., 2005) (Furusho, Jin et al., 2009). It has three ER fluid brakes and one ER fluid clutch, i.e., it is a passive system with couple of redundant brakes.

All connections between brakes and links are by belt-pulley systems with timing belts (toothed belts). It has advantages in high power-transmitting ratio and little backlash. Link 1 (angle $9_{1}$ ) and Link 2 (angle $9_{2}$ ) are connected to ER fluid brake 1 and ER fluid brake 2 by belt-pulley respectively. Rotate angle of ER fluid brake 3 is $9_{3}\left(9_{3}=9_{1}+9_{2}\right)$ and rotate angle of ER fluid clutch is $94\left(\begin{array}{l}94=-9 \\ 1+9\end{array}\right)$.

The system has high-resolution encoders to detect the link posture or the handle position. The length of Link 1 and Link 3 is 0.25 [m]. The handle has a force sensor to detect the force from the operator. The size of the base part (excluding the links and the handle) is approximately $0.60 \times 0.60 \times 0.35[\mathrm{~m}]$.

\subsection{Performance Evaluation Method of Passive-Type Force Display and Rehabilitation System with Redundant Brakes}

A: Definition of Lower bound angle a1 and upper bound angle a2 of resistance forcing angle

As shown in Fig. 44, let us consider resistance force that could be represented in the 2-DOF passive-type force display system. The hatching shows the range of resistance force when the velocity of handle is $\mathrm{V}$. The opposite direction to the motion $\mathrm{V}^{\prime}$ is assumed to be a standard direction of resistance force and anti-clockwise is assumed to be a positive direction. The forcing angle $a$ is defined with the angle between resistance force and $V^{\prime}$. The lower bound angle within the range of resistance forces is assumed to be $\mathrm{a}_{1}$ and the upper bound angle is assumed to be $a 2$. Obviously $a 1<a 2$. The relationship between resistance forces and a1, a2 is shown in Table 4. Resistance force with two sides can be displayed only when $a 1<0$ and $a 2>0$. Moreover, the greater a difference between upper bound angle $a 2$ and lower bound angle a1 is, the wider the range of resistance force that can be displayed is. 


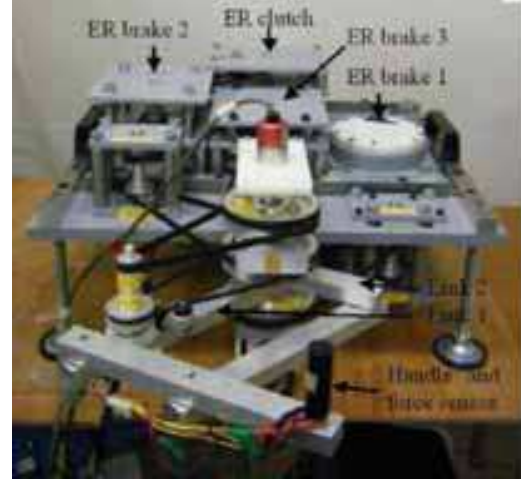

Fig. 43. 2-DOF passive-type force display system with redundant brakes.

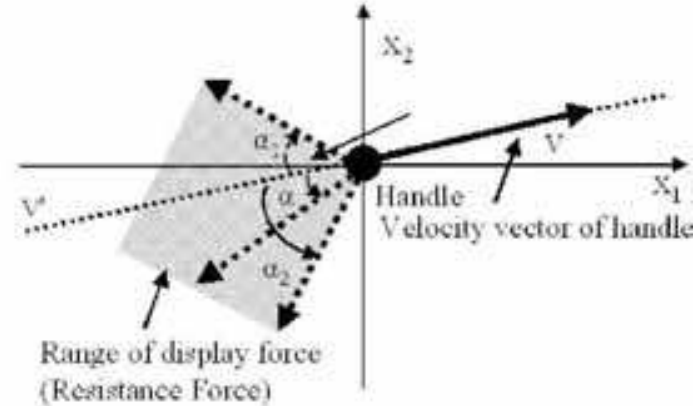

Fig. 44. Resistance force in 2-DOF passivetype force display system.

\begin{tabular}{lll}
\hline & $\alpha_{2}<0$ & \multicolumn{1}{c}{$\alpha_{2}>0$} \\
\hline$\alpha_{1}<0$ & $\begin{array}{l}\text { Resistance force with only one } \\
\text { side can be displayed. }\end{array}$ & $\begin{array}{l}\text { Resistance force with two sides } \\
\text { can be displayed. }\end{array}$ \\
$\alpha_{1}>0$ & NONE. & $\begin{array}{l}\text { Resistance force with only one } \\
\text { side can be displayed. }\end{array}$ \\
\hline
\end{tabular}

Table 4. Relation between Resistance Force and $\alpha_{1}, \alpha_{2}$

\section{B: Performance Evaluation Method}

Fig. 45. Angle Graph of $a_{1}, a_{2}$.

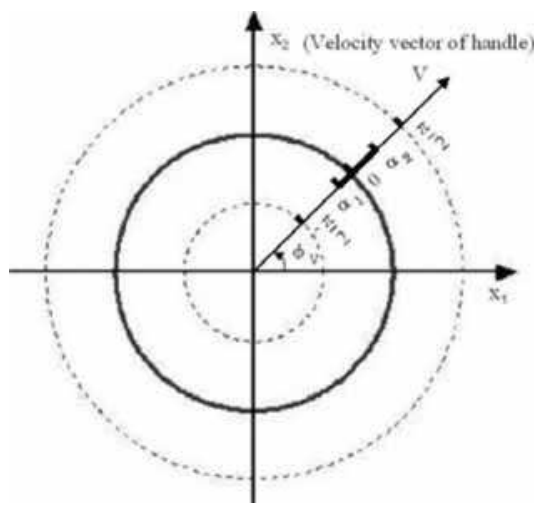

Lower bound angle $\mathrm{a}_{1}$ and upper bound angle $\mathrm{a}_{2}$ is demonstrated in Fig. 45 . Circle 0 means a $=0$ (radian), i.e., the direction 0 (radian) is the opposite direction to the motion (as shown in Fig. 45). Circle - it $/ 2$ and circle it $/ 2$ mean $a=$ it $/ 2$ and $a=-$ it $/ 2$ respectively, i.e., the direction 
is vertical to the motion. Resistance force is drawn as the solid line, and the range of resistance force is between cti and $\mathrm{a}_{2}$, i.e., $\mathrm{a}_{2}$-ai.

\section{C: Simulation}

1) ER fluid brake 1 and ER fluid brake 2 working without redundant brakes Fig. 46 shows the simulation results when handle is at the position of $(0.0,0.45)$. The opposite direction to the motion cannot be displayed with two side when handle is at the sections of A, B, C or D. Fig. 47 shows the simulation results when handle is at $(0.1,0.25),(0.1,0.45),(-0.1,0.25)$, and $(-$ $0.1,0.45)$ respectively. We can see that it is impossible for resistance force to be displayed with two sides in all direction of handle.

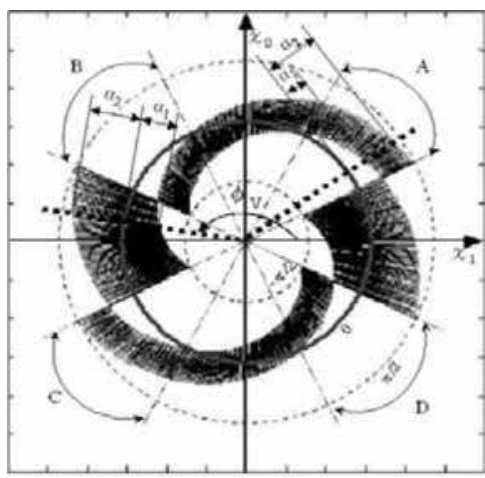

Fig. 46. Angle graphs $\left(\mathrm{x}_{1}=0 \mathrm{~m}, \mathrm{x}\right.$ ${ }_{2}=0.45 \mathrm{~m}$; without redundant brake)

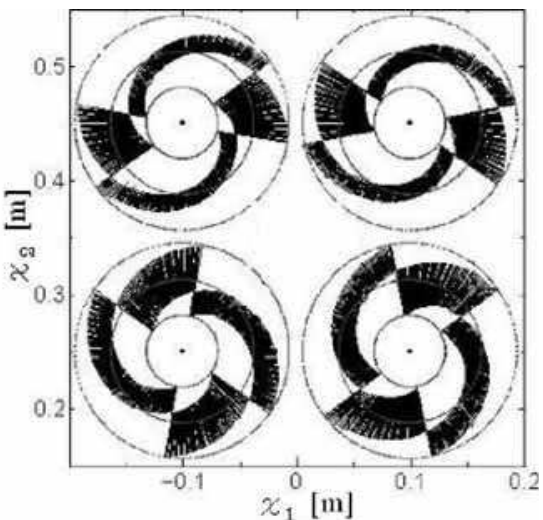

Fig. 47. Angle graphs (without redundant brake)

2) ER fluid brake 1 and ER fluid brake 2 working with redundant brake 3

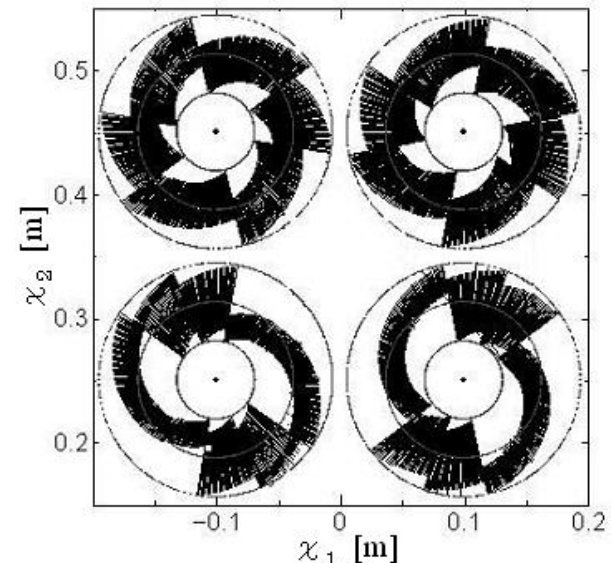

Fig. 48. Angle graphs (with one redundant brakes

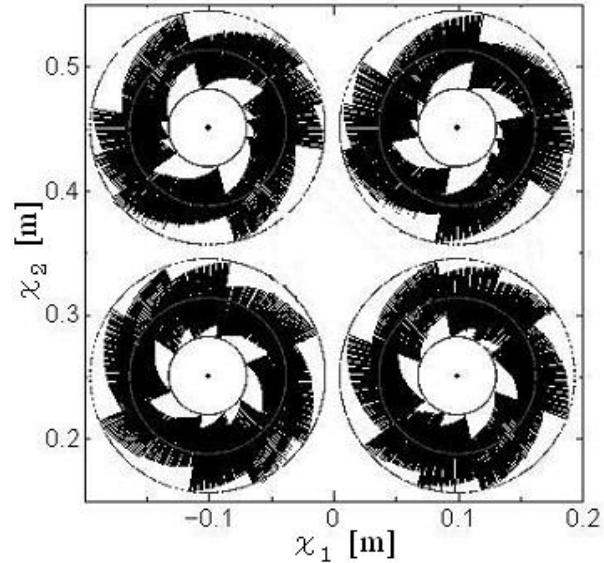

Fig. 49. Angle graphs (with two redundant brakes) 
Fig. 48 shows the simulation results when handle is at $(0.1,0.25),(0.1,0.45),(-0.1,0.25)$, and ($0.1,0.45)$ respectively. It is impossible for resistance force to be displayed with two sides in all direction of handle when handle is at the position of $(-0.1,0.25)$, and $(-0.1,0.45)$. ER fluid brake 1 and ER fluid brake 2 working with redundant ER fluid brake 3and ER fluid clutch Fig. 49 shows the simulation results when handle is at $(0.1,0.25),(0.1,0.45),(-0.1,0.25)$, and ($0.1,0.45)$. We can see that it is possible for resistance force to be displayed with two sides in all direction of handle when handle is at the position of $(-0.1,0.25)$, and $(-0.1,0.45),(-0.1,0.25)$, and $(-0.1,0.45)$.

\section{Isokinetic Exercise System Using High Performance MR Fluid Brake}

\subsection{Introduction}

IN recent year, several kinds of training method, for example, "isometric", "isotonic", and "isokinetic" exercise are used in muscle strengthening training depending on the contractile types of their muscles (Verrill, Shoup et al., 1992).

In an isometric contraction, the angle of a joint is fixed, and the length of muscle is also fixed constantly. At specific angle of joint, subjects is required to generate their maximal muscle strength. In this type, we can measure maximal torque of muscles, but can not measure dynamic properties of them. On the other side, in the isotonic contraction, constant weights are loaded on the muscle. In this type, we can measure dynamic properties of muscles but can not measure maximal torque. In order to solve this problem, isokinetic exercise was suggested. We can measure maximal torque at any angle of joint dynamically, because in this method, subjects required to generate maximal torque during whole range of motion under the restriction of velocity with special training machine which can develop exact velocity control.

As mentioned above, we need the isokinetic exercise machine to develop exact isokinetic exercise. Conventionally, actuator-type (Bohannon, 1991 and Kelli \& Baltzopoulos, 1996) was used in clinical field, but these system cost expensive depending on its actuation device (actuator is usually servomotor with high torque) and safety system.

In order to develop an isokinetic exercise machine with low-cost, high safety and high performance, we have developed isokinetic exercise machine using ER Fluid Brake (Furusho, Sakaguchi et al., 2002) (Kikuchi \& Furusho, 2003). In this brake-type machine, driving force is generated from human itself, and velocity control is conducted with only braking torque of the controllable brake. We could reduce its inertia and realized very high speed isokinetic exercise at $800 \mathrm{deg} / \mathrm{s}$ with this system. However, we had to change reduction ratio depending on the target velocity because of a loss of dynamic range of the ER Fluid Brake.

In this report, we describe development of isokinetic exercise system using a MR fluid brake. By the contribution of wide dynamic range of MR fluid brake, we can conduct wide range of the training velocity (from 0 to more than $800 \mathrm{deg} / \mathrm{s}$ ). At the same time, we can conduct the velocity control with high accuracy thanks to the high performance (time constant of torque is about 5 milliseconds) of the MRF brake.

Additionally, we suggest iso-contractile mode using this system. Basic idea of this mode and experimental result is presented at the end part of this section. 


\subsection{Muscle Exercise Machine Using Brake}

\section{A: MR Fluid}

Magneto-Rheological (MR) fluid is a kind of functional fluids that are attracting much attention these days. This fluid is composite material of non-colloidal solution and magnetic metal particles (e.g., iron particles). The diameter of the particle is 1-10 micrometers. The fluid changes its apparent viscosity (a rheological characteristic) when a magnetic field is applied to it (Carlson \& Jolly, 2000). The response of changing the viscosity is very rapid (about several milliseconds). The MR Fluid used in this study is MRF-132DG, which is developed by LORD Co., USA.

Fig. 50 shows how the shear stress changes with the shear rate as the magnetic field in the MR fluid. The fluid presents the characteristics of Newtonian fluid when no magnetic field is applied $(\mathrm{H}=0)$, as shown by the dashed line in Fig. 50 . When the magnetic field is applied $(\mathrm{H} \# 0)$, the fluid has its viscosity greatly changed, presenting the characteristics of Bingham fluid, as shown by the solid line in Fig. 50. In particular, the shear stress is almost independent of the shear rate, but changes with the magnitude of the magnetic field. In other words, the magnetic field generates a force between two plates, which can be represented by a Coulomb friction model. Making use of this characteristic, we developed a brake and a clutch-type actuator (Takesue, Furusho, et al., 2004).

B: High Performance MR Fluid Brake (Kikuchi, Furusho et al., 2006) ( Oda, Isozumi et al., 2009)

An MR Fluid Brake (or MRF brake) consists of discs with an output shaft, MR fluid (or MRF), electromagnetic coil, and a fixed cover as shown in Fig. 51. When a current is applied to the coil, the magnetic field is generated in the MRF, and then the viscosity of the fluid increases. This increase of viscosity generates the braking torque and reduces the rotational speed.

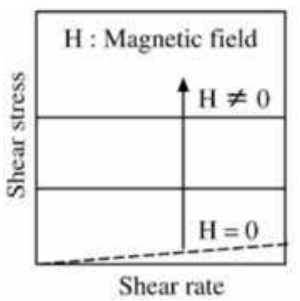

Fig. 50. Characteristics of MR fluid



Fig. 51. Basic structure of MR fluid brake.

The MRF brake has high response because MRF has high response itself. Moreover, MRF brake has good back-drivability. In off-stage of the magnetic field, MRF brake generates little force because of the off-state characteristics of MR fluid.

In this study, four C-type yokes were built around the disc of the MRF brake. The coils were rolled around each yokes. The yokes became the main path of magnetic flux. However, when the magnetic flux density passing through the electric conductor changes, electromotive force is induced and the eddy current passes through the conductor. Due to the eddy current, a counter-magnetic field that opposes the change in flux is produced and the response becomes slower. The magnitude of eddy current depends on the width of the conductor as shown in Fig. 52. In order to reduce eddy current, we use the yoke that is laminated thin silicon steel sheets as shown in Fig. 53. Each sheet is insulated from others. 
The structure and specification of the MRF brake are shown in Fig. 54 and Table 5, respectively.
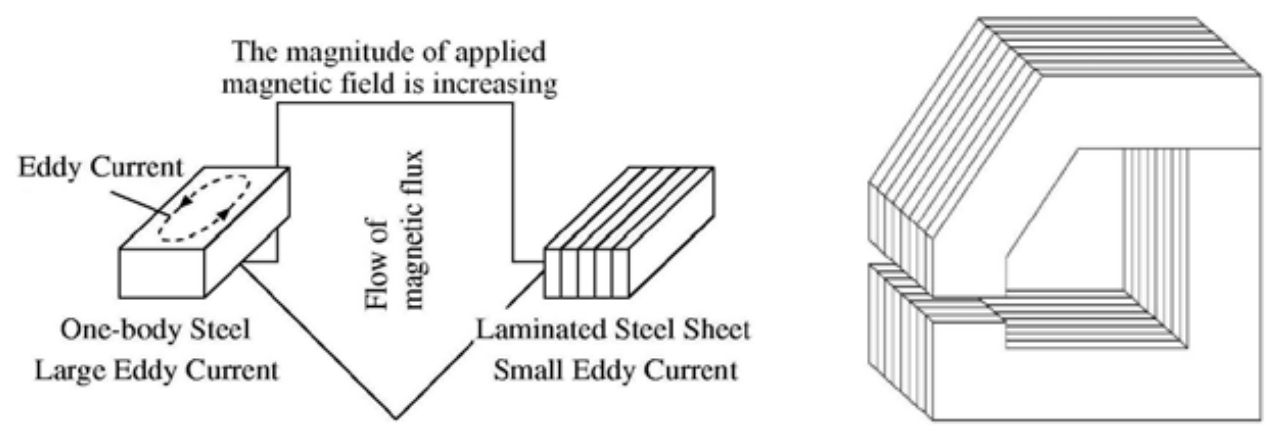

Fig. 52. Magnitude of eddy current depends on the width of conductor.

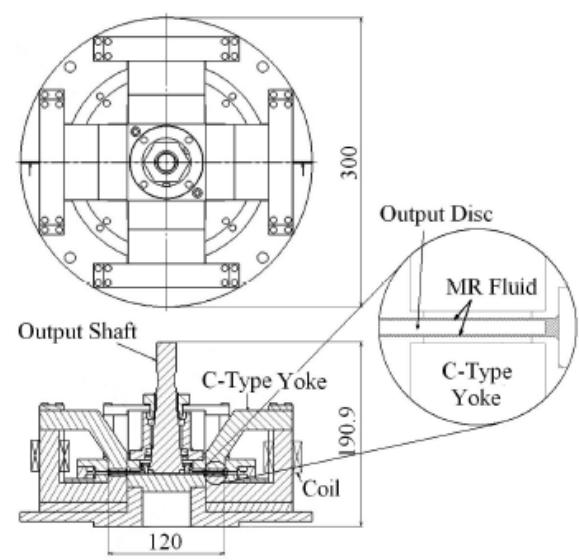

Fig. 54. Structure of MRF brake.
Fig. 53. C-Type yoke laminated silicon steel sheet.

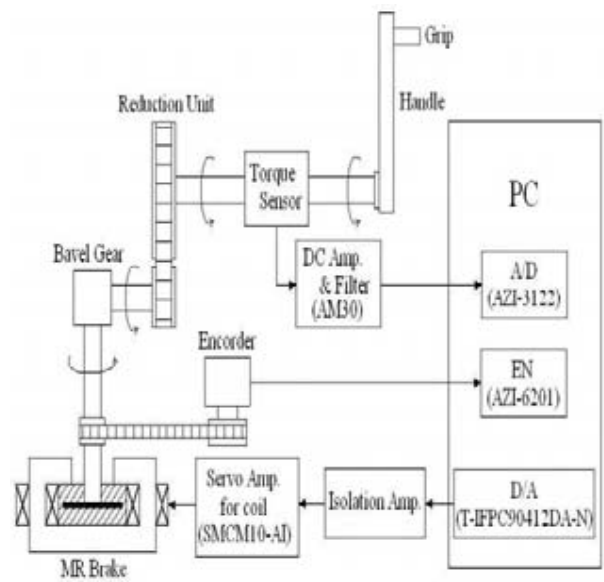

Fig. 55. Diagram of the training system.

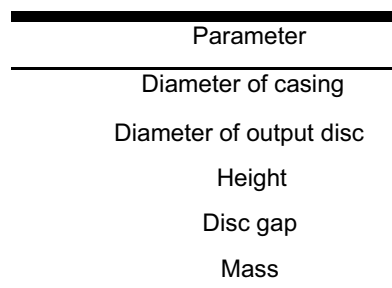

Num. of yoke

Turn num. of coil

Max. input current

Max. braking torque

\begin{tabular}{c} 
Value \\
\hline $300 \mathrm{~mm}$ \\
$120 \mathrm{~mm}$ \\
$190.9 \mathrm{~mm}$ \\
$0.4 \mathrm{~mm}$ \\
$26.4 \mathrm{~kg}$
\end{tabular}

4

400turn

$2 \mathrm{~A}$

$27.5 \mathrm{Nm}($ at $2 \mathrm{~A})$

Table 5. Specification of MR Brake. 


\section{C: Muscle Exercise Machine Using MRF Brake}

We have developed an isokinetic exercise system using an ERF brake (Kikuchi, Furusho et al., 2003). In this section, we develop an isokinetic exercise system using MRF brake. The diagram of the basic system is shown in Fig. 55, and shows its appearance. By using this system, isometric, isotonic and isokinetic exercises can be conducted. Moreover, at these exercises, we can conduct both directions, that are flexion or extension, for both hands; right or left.

As shown in Table 6, we can control the load of $27.5 \mathrm{Nm}$ directly using the MRF brake, but it will not be enough for whole range of training. Therefore we determined to install a reduction system between the brake and an operation section. The reduction system was designed using a belt-pulley mechanism. The reduction ratio of this system was decided as $1 / 4.41$ to generate more than $90 \mathrm{Nm}$. This goal was made based on the data of an average of 19-year-old men from a human-database (Shuppan, 1992).

This machine is very safe because any active device is not used for its velocity control. Driving force is generated from human itself, and rotational velocity is controlled with the braking torque of the MRF brake accurately. Specifications of the system are shown in Table 6.

Fig. 56. Appearance of MEM-MRB.

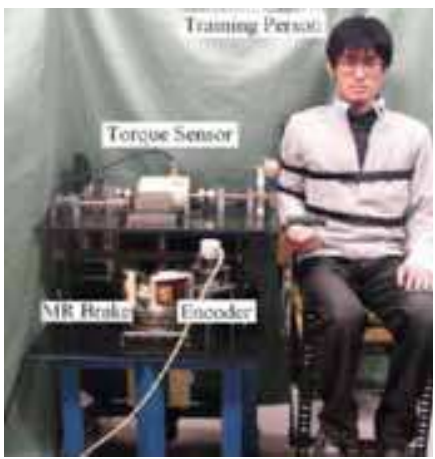

\begin{tabular}{cc}
\hline Parameters & Definition \\
\hline Reduction ratio & 4.41 \\
Max. breaking torque & $120 \mathrm{Nm}$ \\
Training direction & Both(flexion, extension) \\
Training side of band & Both(right, left) \\
\hline
\end{tabular}

Table 6. Specification of the system

\subsection{Characteristics on Isokinetic Mode A: Motivation and theory}

It is known that the relation called a force-velocity curve is established between the output force of a muscle and a joint velocity. The model drawing of the force-velocity curve is shown in Fig. 57. 
The case of the zero joint velocity is called an "isometric contraction." In the isometric contraction, the joint is fixed but inside the muscle, muscle fibers are shortened and elastic sites such as a tendon are extended.

The case of the negative velocity of the joint while generating the force, that is to say, the state of the joint movement toward an opposite direction of the output force is called an "eccentric contraction." This corresponds to the negative zone of the velocity in Fig. 57. The maximum muscle force in the eccentric contraction is larger than the maximum muscle force in the isometric contraction, but forcing the joint to elongate leads to a rupture of the muscle fiber and a destruction of the joint.

On the other hand, the case of the positive velocity of the joint while generating the force, that is to say, the state of the joint movement toward the same direction with the direction of the output force is called a "concentric contraction." This corresponds to the positive zone of the velocity in Fig. 57. In the case of the concentric contraction, the output force decreases with the increase of the joint velocity and exceeding certain joint velocity leads to the zero output force. This curve under the concentric contraction is formulated by A.V.Hill (Hill, 1939) as:

$$
\mathrm{V}=\mathrm{b}(\mathrm{P} 0-\mathrm{P}) /(\mathrm{P}+\mathrm{a})
$$

where $\mathrm{P}$ is the force, $\mathrm{V}$ is the velocity of a contraction of a muscle, $\mathrm{P} 0$ is the force at the isometric contraction, and $\mathrm{a}$ and $\mathrm{b}$ are parameters depending on each muscle. This equation is called "Hill's equation" or "Hill's curve".

As such a relationship holds between the output force of the muscle and the joint velocity, a quantitative evaluation is possible if the maximum output force of the muscle at each joint velocity could be measured under the isokinetic mode.

\section{B: Control method}

The control system for the isokinetic mode is shown in Fig. 58. PI controller was used for its velocity control. KP and KI mean a proportional gain [Nm's/rad] and an integral gain $[\mathrm{Nm} / \mathrm{rad}]$, respectively, and $\mathrm{G}(\mathrm{s})$ means a transfer function of the controlled object (MRF brake). TO, TB, and $\infty$ mean an operation torque $[\mathrm{Nm}]$, the brake torque $[\mathrm{Nm}]$, and the angular velocity of elbow $[\mathrm{rad} / \mathrm{s}]$, respectively.

The output torque acts toward only an opposite direction to the rotational direction, and if the operator gives enough torque during the training, the output torque direction required for the brake is an opposite direction of the rotational direction.

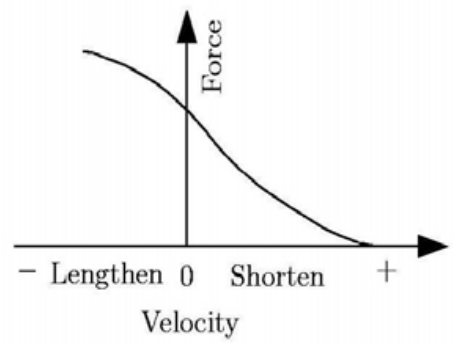

Fig. 57. Force-velocity relation of muscle.

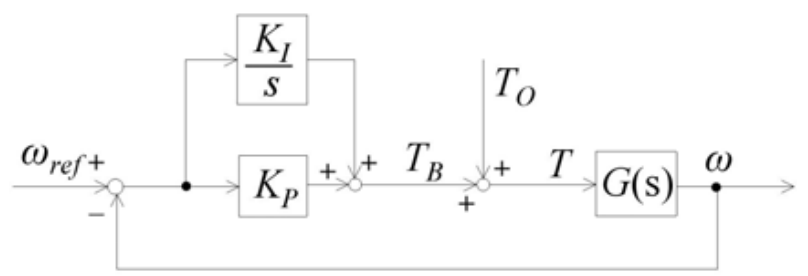

Fig. 58. PI controller for velocity control. 


\subsection{Suggestion for the Iso-contractile Mode}

\section{A: Motivation and Model}

In conventional researches about the isokinetic exercise, only angular velocity of joints was controlled (or kept constant). But in basic experiments of muscles, for example Hill's experiments (Hill, 1939), the velocity-force relationship under the linear contraction have been measured. We have to control the linear contractile velocity of muscles if we want to reveal the real velocity-force relationship in vivo.

When we rotate a joint, several muscles work concurrently during its motion. At the same time, joint movements are generally complex because they include both of rolling action and sliding action. Therefore, it is difficult to control velocities of particular muscles with controls of single joints. However, if we focus on the elbow flexion, we can approximately control the contractile velocity of a biceps brachii muscle. The reasons are as follows:

(1) In the elbow flexion, three muscles (biceps brachii, brachialis and brachioradialis) work concurrently. However, the contraction force of the biceps brachii is overwhelmingly larger than others.

(2) Basically, the biceps brachii is a two-joint muscle corresponding to an elbow joint and a shoulder joint. However, if we fix the angle of the shoulder joint, the biceps brachii works as a one-joint muscle corresponding to only the elbow joint.

(3) Elbow joints are exactly single-axis joint without sliding actions

Due to these reasons, we can make a simple model of the elbow flexion as shown in Fig. 59. In this figure, 0 and a mean an elbow angle and an angular velocity of elbow, respectively. Additionally, $\mathrm{L}$ and $\mathrm{r}$ mean a length and lever arm of biceps brachii, respectively. Under this assumption, $\mathrm{L}$ and a can be calculated as following equations;

$$
\begin{gathered}
L=\sqrt{R^{2}+r^{2}-2 R r \cos \theta} \\
\omega=\frac{-R r \sin \theta}{\sqrt{R^{2}+r^{2}+2 R r \cos \theta}} \frac{d L}{d t}
\end{gathered}
$$

In conventional isokinetic exercises, a was kept constant with the velocity control of instruments. But we can control the contractile velocity of the biceps brachii muscle $(d L / d t)$ with equation (3). We call this mode "iso-contractile" mode in this section.

\section{B: Basic method for Iso-Contractile Control}

Iso-contractile control can be simply conducted with the velocity control of our muscle exercise machine and a reference angular velocity curve which calculated from equation (3). Fig. 60 shows an example of the reference velocity curve of the constant contractile velocity of $200 \mathrm{~mm} / \mathrm{s}$. In this case, R and r of Fig. 59 were set to $0.3 \mathrm{~m}, 0.03 \mathrm{~m}$, respectively. A dashed line means a contractile velocity of the biceps brachii. As you see it, the contractile velocity is constant. On the other hand, a solid line means a reference velocity of the elbow joint. As you see in this line, the reference velocity becomes a concaved curve. 


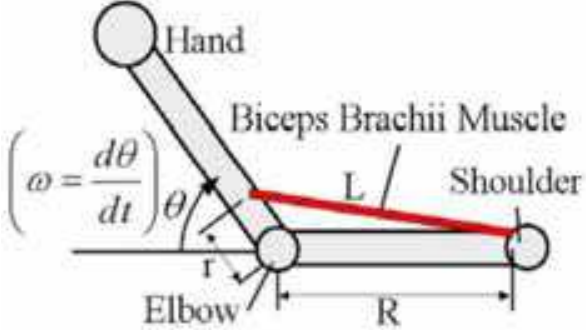

Fig. 59. Simple model of the elbow flexion.

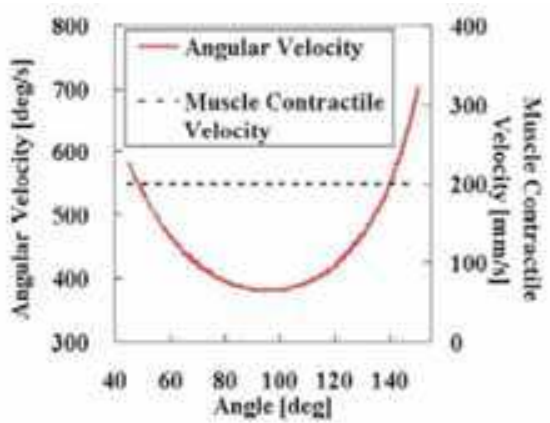

Fig. 60. Reference curve of angular velocity at the muscle contractile velocity of $200 \mathrm{~mm} / \mathrm{s}$

\section{Intelligently-Controlled Prosthetic Ankle Joint Using MR Fluid}

We realized the first walking with kick action in biped robots using "BLR-G"(shown in Fig. 61) (Furush\&Sano,1990). In this robot the ankle torque was sophisticatedly controlled. At present we are studying the control of ankle torque of prosthesis and orthosis.All prosthesis users need "foot" part. This part moves so frequently and widely that it needs to be as light as possible. It also must be silent and strong because it is used in daily life. If stiffness or spring characteristics of prosthesises can be changed according to the timing of walking and dorsiflection can be kept adequately, it will be much easier for users to walk and run. Now, shapes of prosthetic sockets have been improved and the range of actions of prosthesis has varied. Also, a lot of intelligent prosthetic knees have been developed and are sold on the market. But none of prosthesis that can control the ankle was on the market. Fig. 62 shows an example of a prosthetic "foot" part. It is composed of a prosthetic ankle joint and a footankle unit. Energy of movement stored at the elastic part (rubber) of the prosthetic ankle joint is relieved when kicking, producing driving force. This rubber can also absorb shocks when the heel hits on the ground, and changing the angle smoothly. After kicking back, a leg leaves from the ground and swings forward during swing phase. Then the rubber goes back to its balanced midpoint, which makes the ankle turns instantly from the dorsal direction (deflecting a tiptoe upward, as shown in Fig. 62 (a)) to the plantar direction (swaging a tiptoe underneath, as shown in Fig. 62 (c)). 

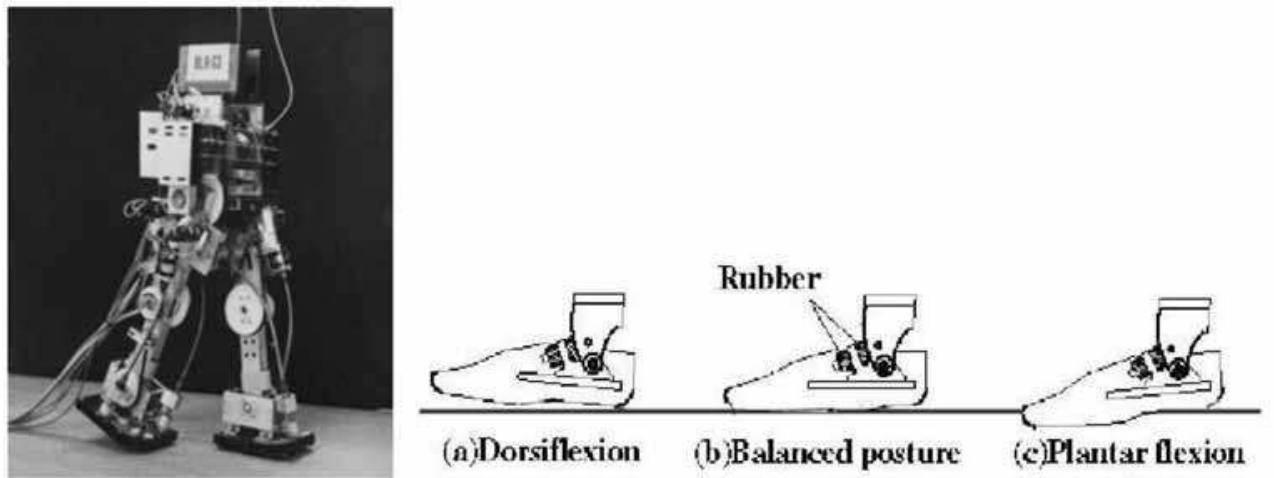

Fig. 61. Biped Locomotion Robot BLR-G

Fig. 62. Prosthetic foot.

Since there is a problem that the tiptoe of the prosthesis tends to collide on the ground (shown in Fig. 63), users have to walk paying attention to lifting legs in order not to tumble. This is why users walk unnaturally causing to use unnecessary energy. To solve this problem, we suggest setting a linear brake at "foot" part.

The MR (Magnetorheological) fluid has been used for the linear brakes. Fig. 64 shows a schematic of MR Linear Brake (MRLB). MRLB consists of a piston composed of two rods, a bobbin sandwiched by the rods on both sides, and MR fluid inside a cylinder. When electric current is applied to the coil which rolls the bobbin, magnetic field is generated in loops as follows; Bobbin ${ }^{\wedge} \mathrm{MR}$ fluid ${ }^{\wedge}$ Cylinder ${ }^{\wedge}$ MR fluid ${ }^{\wedge}$ Bobbin.

We developed two prototypes of the intelligent prosthetic ankle joint using MR brakes (Furusho, Takesue et al., 2004), (Li, Furusho et al., 2006), (Li, Tokuda, Furusho et al., 2006). Fig. 65 shows the 2nd prototypes. Fig. 66 and Fig. 67 show the series of static images extracted from moving images of the walking experiments. Circles around the ankle in these figures show the test subject's left leg (a swinging leg).

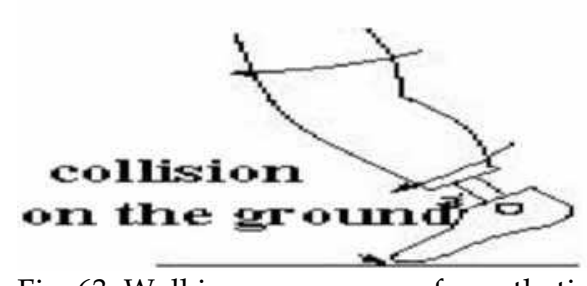

Fig. 63. Walking appearance of prosthetic foot during swing phase.

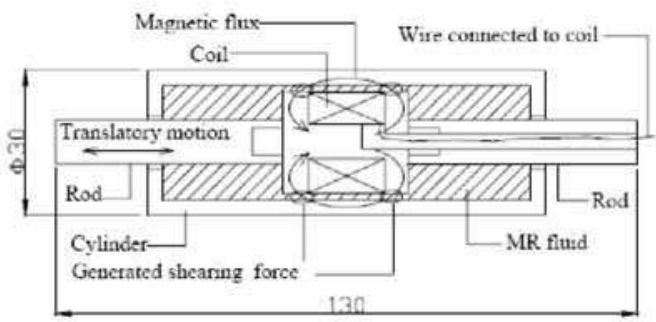

Fig. 64. Construction of MR Linear Brake. 


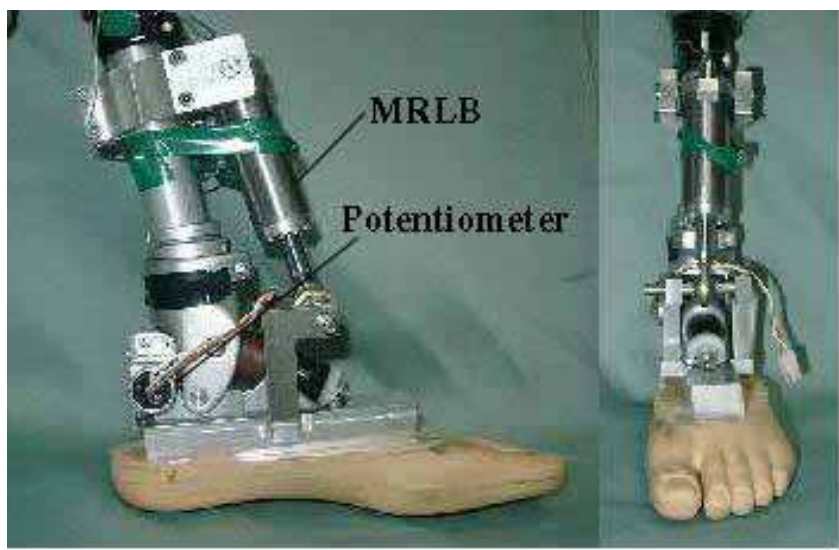

Fig. 65. 2nd prototype.

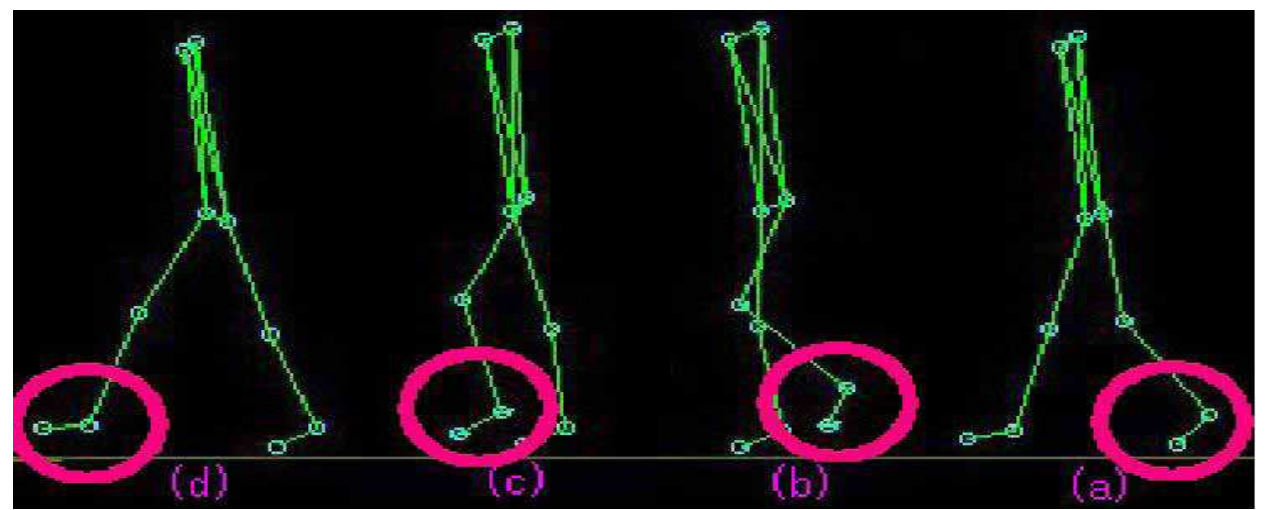

Fig. 66. Walking positions with brake control.

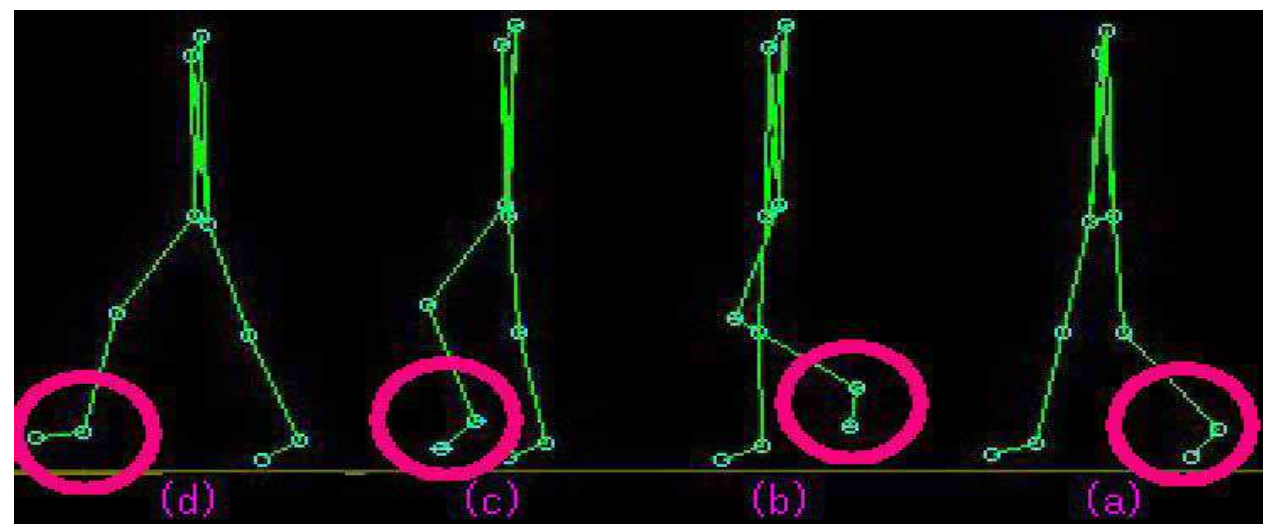

Fig. 67. Walking positions without brake control. 
The subject's impressions of experiments with 2nd prototype are as follows: "I felt easier to walk by keeping dorsiflexion. I didn't care the total weight only for some hours, but if I use it in my daily life all day, it will be a load for me ".

\section{Intelligent Ankle-Foot Orthosis with Shear-type MR Fluid Brake}

Recently, as habits of people has changed, stroke patients tend to increase. There are many cases of the hemiplegia as aftereffects of a stroke. Stroke patient with hemiplegia show difference in the degree by a part and a range of a lesion caused by a disease, however rehabilitation is indispensable to restore functional disorder of lower limbs. We are developing intelligent ankle-foot orthoses using shear-type MR fluid brakes in a 3-year NEDO project (Furusho, Li et al., CME2007) (Furusho, Kikuchi et al., ICORR2007). Fig. 68 shows a conceptual illustration of shear-type MR fluid brakes. A coil rolled round a shaft give an MR fluid a magnetic field. Scroll number of coils and spindle diameter are decided by performing magnetic field analysis. As for materials of each part, magnetism materials are used in a magnetic circuit part. In addition, a housing is made of a nonmagnetic body, to avoid the magnetic flux from leaking.

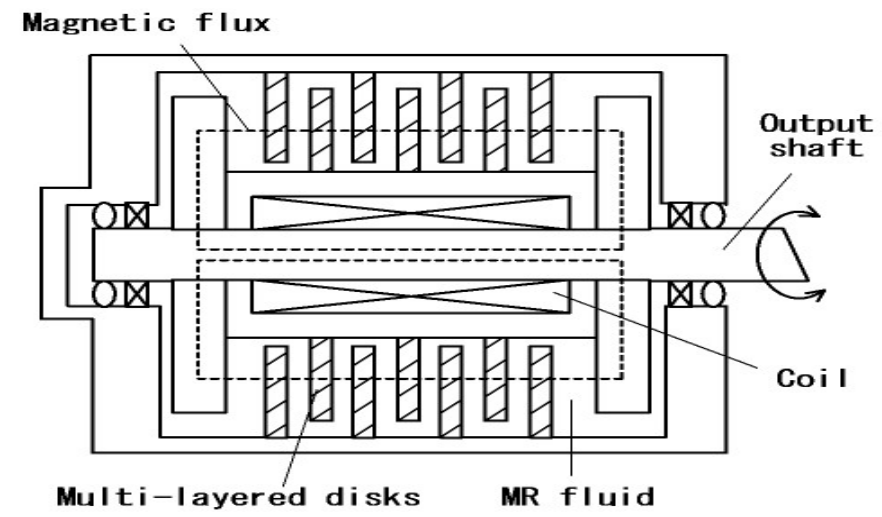

Fig. 68. Structure of MRB. 


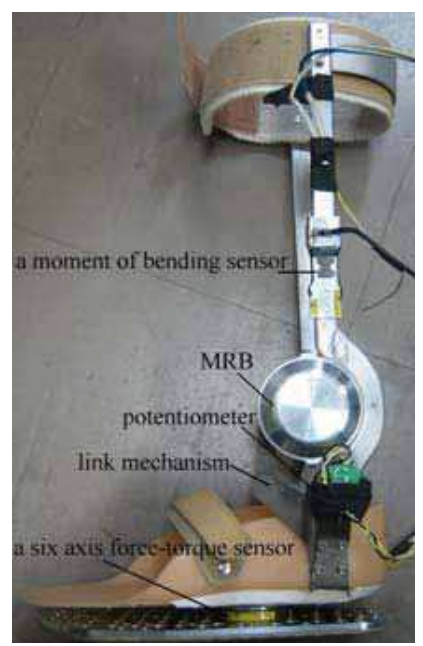

Fig. 69. Ankle-foot orthosis.

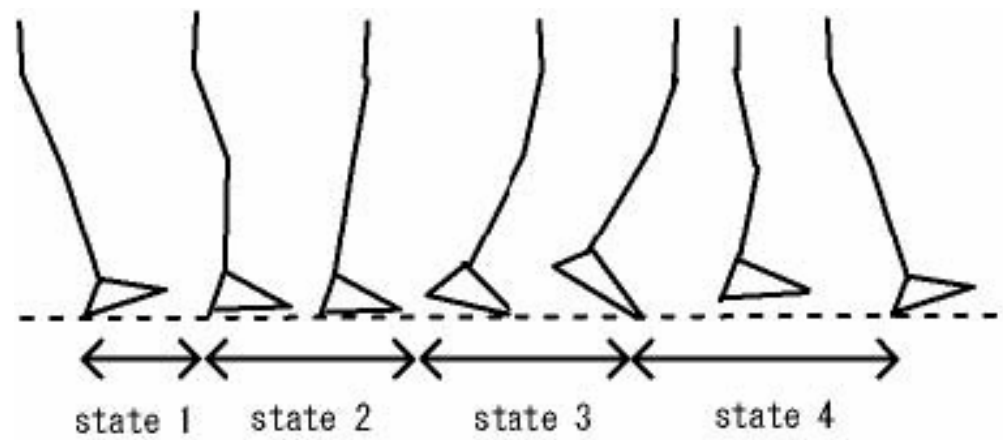

Fig. 70. Walking State.

Fig. 69 shows the second Prototype of intelligent ankle-foot orthosis using the shear-type MR fluid brake. We obtain the maximum torque of $24[\mathrm{Nm}]$ with the idling torque of $0.1[\mathrm{Nm}]$. We use four sensors: potentiometer on the ankle, 6-axis force-torque sensor at the center of a foot bottom, a moment of bending sensor and an acceleration sensor on the prop part of an orthosis side. We divide a walking step into four; into heel reaching the ground, tiptoe reaching the ground, heel leaving ground, tiptoe leaving ground (shown in Fig. 70). These states are detected by using the above sensors, and then the brake torque is controlled in accordance with each state. 


\section{Intelligently Controllable Ankle Foot Orthosis (I-AFO) and its application for a Patient of Guillain-Barre Syndrome}

\subsection{Introduction}

LOCOMOTION is most important skill of the activity of daily living (ADL) for human. Therefore gait training is made a high priority in rehabilitative training.

Normal gait is cyclic and can be characterized by timing of foot contact with the ground; an entire sequence of functions by one limb is identified as a gait cycle (Cappozzo, 1984 and Inman, Ralston et al., 1981) (shown in Fig. 71). Each gait cycle has two basic components: "stance phase," which designates the duration of foot contact with the ground, and "swing phase," the period during which the foot is in the air for the purpose of limb advancement. The swing phase can be further divided into three functional subphases: "initial swing," "mid swing" and "terminal swing." In the same manner, the stance phase can be partitioned into five functional subphases: "initial contact," "loading response," "midstance," "terminal stance" and "preswing" (Bampton, 1979 and Esquenazi \& Hirai, 1991). In the normal gait, initial contact becomes "initial contact (or heel-contact)," appropriately. And in the initial swing (or "toe-off"), normal subjects can keep appropriate clearance from the ground to prevent a malfunctional interaction with the ground. For patients who have dysfunction of ankles, for example hemiplegia, central nerve injury, polio or peroneal nerve palsy, it is difficult to control their ankle by themselves. This problem causes "equinus foot" or "drop foot", which are lacks of ankle dorsiflexion during the swing phase. In many case, they can not prevent from tripping their toe on even small steps on the ground. Additionally, they have a tendency to incline their body more than healthy persons because of the rough motion to prevent from stumbling of the toe. It causes undesired energy-loss in walking.

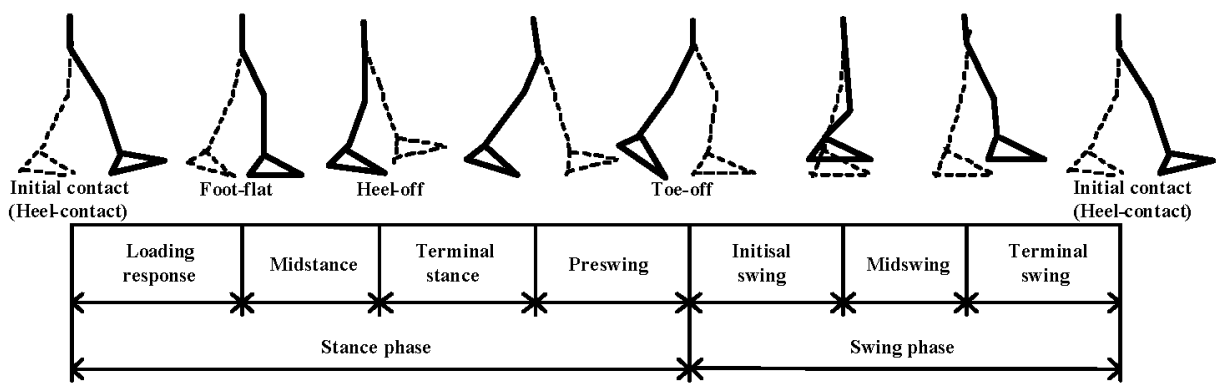

Fig. 71. Normal gait cycle.

An orthosis is defined as a device attached or applied to an external surface of a body to improve functions, restrict or enforce, or support a body segment (Redford, 1984). In order to improve the gait of the patients, lower limb orthoses are applied to them. In order to assist their ankle function, ankle-foot orthoses (AFOs) are often used to restrict their involuntary plantarflexion and so on.

Recently, powered AFOs have been focused on. Some kinds of the powered AFO were reported (Aaron \& Hugh, 2007) by using several types of actuators, e.g. pneumatic actuation system (Keith \& Daniel, 2007), ball screw drive system (Bashir \& Arafat, 2006), series elastic actuator (Joaquin \& Hugh, 2004), and so on. 
In this study, we suggest the passive controllable AFO with a compact brake devise for a dynamic gait control. In particular, the control of drop-foot can be realized by only using passive devices. The passive controllable AFO also have a great advantage for cost, safety and downsizing. In our previous research (Furusho, Kikuchi et al., 2007), we developed some kinds of intelligently controlled AFO (I-AFO) which can control ankle torque with compact magneto-rheological fluid brakes (MRB) (Carlson \& Jolly, 2000). In this paper, we describe the gait-control tests with the I-AFO for a patient of the Guillain-Barre syndrome.

\subsection{Intelligently Controllable AFO (I-AFO)}

\section{A: Components of I-AFO}

Fig. 72 (a) shows the I-AFO reported in the previous report (Furusho, Kikuchi et al., 2007). This I-AFO was developed for the gait control of hemiplegic patients. As shown in this picture, this AFO system has three types of sensing devices as follows;

(1) A potentiometer at the ankle position,

(2) A 6-axis force sensor under a sole,

(3) A bending moment sensor built in a brace.

This system has great advantage to measure several types of information during walking. In previous report, we detected the initial contact (heal contact) with the force (or torque) information. However, the weight of the total system exceeded $1.5 \mathrm{~kg}$, and lightening of the weight is strongly demanded for.

In order to lighten the weight, we improve the sensing system of the I-AFO shown in Fig. 72 (b). In the new sensing system, we detect the initial contact (or other states) with ON/ OFFstates information from two foot switches attached on the heel side and MP (metatarsophalangeal) joint of the sole (see Fig. 73). The reason why we attached a foot switch on the MP joint is because the subject always used the plastic orthosis that was cut out from MP joint to toe.

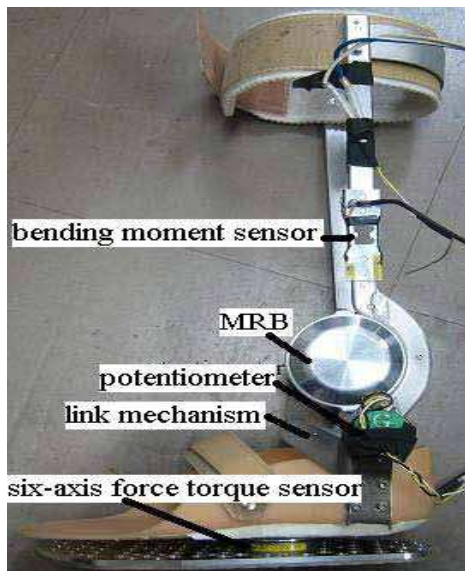

(a) Previous system [11]

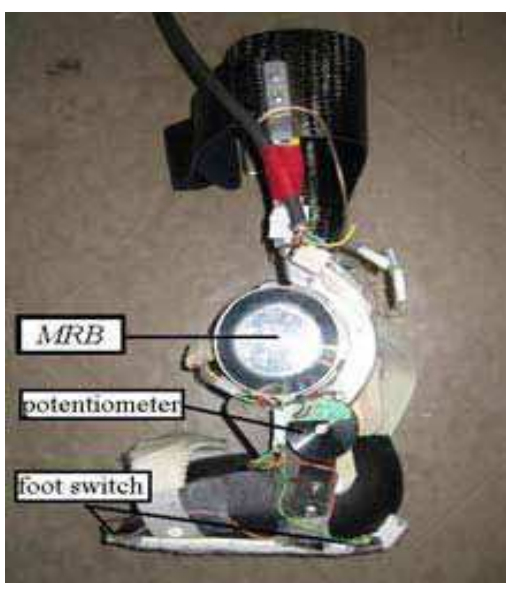

(b) New system

Fig. 72. I-AFO with a MR fluid brake. 


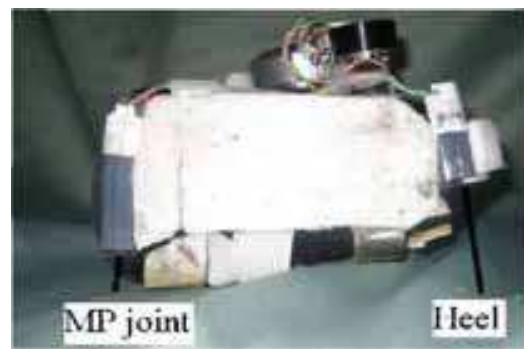

(a) Bottom view

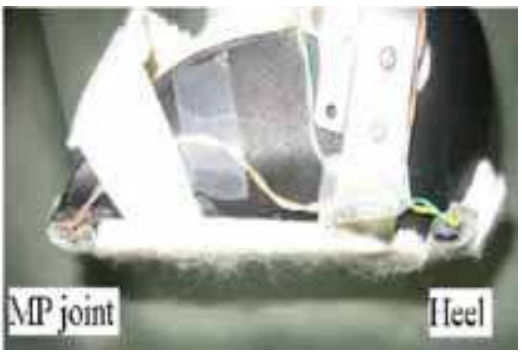

(b)Side view

Fig. 73. Foot switches for contact detection.

In this sensing system, we can not measure the force information, e.g. GRF (Ground Reaction Force) by itself. But in experiments, we measured GRF with a reaction force plate as mentioned at section 3. As result, the weight was decreased from $1.5 \mathrm{~kg}$ to $1.1 \mathrm{~kg}$. Additionally, in the same way of the previous system, an ankle angle is measured with a potentiometer attached on the ankle joint and the ankle torque is controlled with MRB (MR brake). The maximum ankle torque is $12 \mathrm{Nm}$ with applying the electric current of $1 \mathrm{~A}$.

\section{B: Control System}

Fig. 74 shows a picture and signal flow diagram of the control system of the I-AFO. A laptop computer attached with a multi-functional card (A/D and D/A) was used as a controller of this system. The braking torque was controlled by an electric current from a current amplifier in the circuit box. A reference signal to the current amplifier was outputted from the controller (laptop). The signals from tow types of sensors (a potentiometer and foot switches) ware inputted through the A/D card into the controller. The battery provided energy for the sensors and amplifier. Sampling frequency was $125[\mathrm{~Hz}]$.

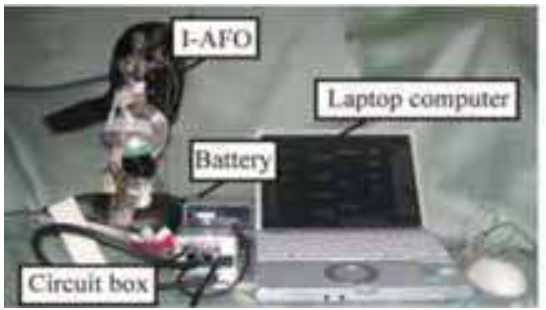

(a) Appearance

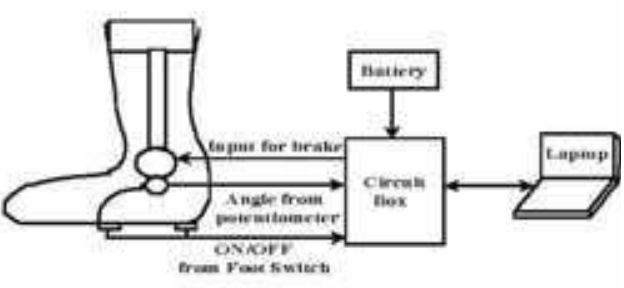

(b) Signal flow diagram

Fig. 74. Control system for I-AFO.

\section{C: Control Method}

Main purposes of the control of the I-AFO are as follows:

(1) To prevent the drop foot in the swing phase and,

(2) To prevent a slap foot and a knee buckling at initial contact.

For convenience, we rename the phases of the gait cycle (shown in Fig. 71) for the control method as following four states;

(1) State 1: from initial contact (IC) to loading response (LR)

(2) State 2: from LR to terminal stance (TSt)

(3) State 3: from TSt to initial swing (ISw) 
(4) State 4: from ISw to IC

Fig. 75 shows a flow diagram of the control method. In the Fig. 75, "MS" means the state of the foot switch on the MP joint and "HS" means the state of that on the heel side. The ON/OFF-states of the foot switches decide the state mentioned above. In a normal gait, control state will shift from "state 1" to "state 4" cyclically as shown in this figure. However, if a subject walks with an abnormal gait, it is possible to pass some states, for example directly changing from "state 2 " to "state 4 ".

Fig. 76 shows a reference signal for the brake torque of the I-AFO corresponding to each state of Fig. 75. At the instant of the initial contact, MR brake generates rapid and strong torque to keep dorsiflexion. After that, the brake torque is gradually decreased during "state 1 ". In the "state 2 ", brake torque is not generated to facilitate smooth movement to forward direction. At the instant of the TSt, the brake generates its torque to keep dorsiflexion. And this torque is kept during "state 3" and "state 4".

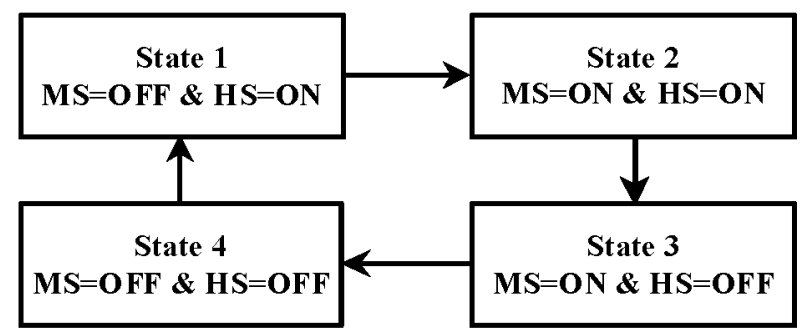

Fig. 75. Flow chart diagram for gait control (normal state)

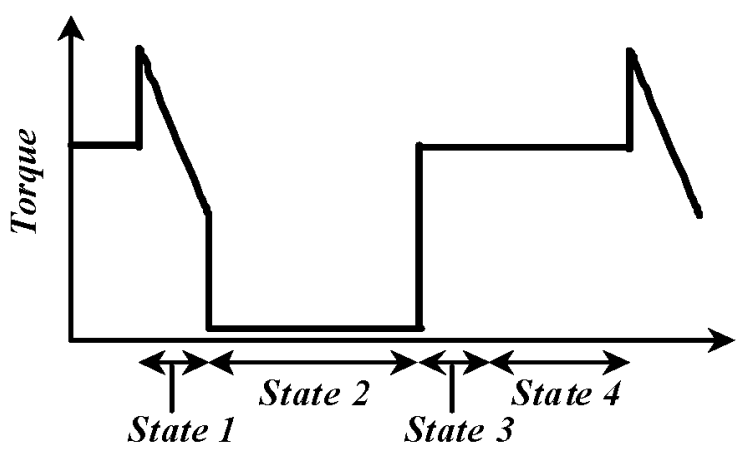

Fig. 76. Reference signal of brake torque.

\subsection{Method}

\section{A: Subject}

The subject was one male patient of the Guillain-Barre syndrome (height: $183.0 \mathrm{~cm}$, weight: $83.1 \mathrm{~kg}$ ). The subject has difficulty with voluntary movement of the peripheral part of the inferior limb, especially ankle joints and toes of both lower limbs. He attaches a plastic AFO in the daily life, for assisting functions of ankle joint. He shows the drop foot in walking. In addition, the disuse muscle atrophy is presented remarkably, too. 
The ROM of the ankle joint of the plantar flexion is 45 degrees. That of the dorsiflexion is 0 degrees. He has restrictions of the dorsiflexion, especially.

\section{B: Data collection}

We made gait experiments on a flat floor and measured it with a three-dimensional movement analysis device (Video Locus 3D: Anima Co. Ltd. Japan) and a reaction force plate (MG2090: Anima Co. Ltd., Japan). The subject walked in three conditions: it is 1) a bare foot walk, 2) a walk with I-AFO (or "I-AFO walk"), 3) a walk with plastic orthosis (or "PAFO walk"). In each condition, the subject performed it at normal walking speed (Walking cycle 1.30sec, Walking rate 92steps / min), fast speed (Walking cycle 1.03sec, Walking rate 116steps / min), and slow speed (Walking cycle 1.72sec, Walking rate 69steps / min). Walking cycle was adjusted with a metronome. Consequently, we measured with nine conditions in total. Before the measurements, the subject performs ambulatory exercise. The subject walked $5 \mathrm{~m}$ from the 3 meter front of the reaction force plate with looking at the front naturally.

Fig. 77 shows the experimental environment. In this set, we installed two infrared cameras in the left side of the subject and captured a view from a sagittal plane. In addition, the reaction force plate was arranged to be put by only left foot. Furthermore, we photographed the gait using a digital video camera (DM - FM M20: Canon Co. Ltd., Japan) from his left side.

The markers for the three-dimensional movement analysis device were put on as shown in Fig. 78 and five markers were used for analyses; I) anterior superior iliac spine (marker 3), II) trochanter major (marker 4), III) knee joint fissure (marker 5), IV) lateral malleolus (marker 6) and V) basis ossis of the fifth metatarsalis (marker 7). We calculated hip joint angle from the infrared marker I), II), III) and knee joint angle from II), III), IV) and ankle joint angle from III), IV), V).

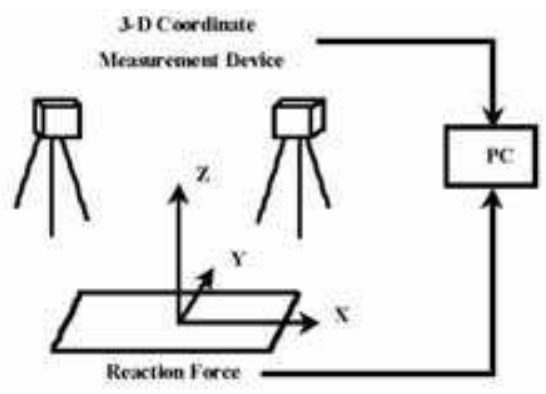

Fig. 77. Experimental environment

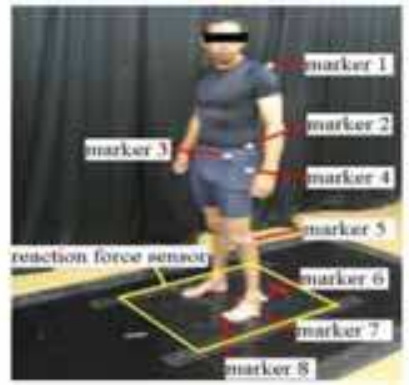

Fig. 78. Subject and markers

About the ethical consideration, we performed informed consent based on its form and managed the personal information severely.

\section{Conclusion}

High safety rehabilitation systems using functional fluid, Robotherapist and other rehabilitation system swere introduced. Robotherapist is a 6-dofrehabilitation system for upper limbs including wrists in the 2-year NEDO Project (2004-2005). EMUL were made in 
the 5-year NEDO project, and they were transferred from NEDO to Furusho Laboratory of Osaka University. We continue clinical evaluation of 3-D rehabilitation system and quasi-3DOF rehabilitation system by using EMUL, Robotherapist and PLEMO.

We have been studying rehabilitation robotics mainly from the standpoint of mechatronics and virtual reality. Hereafter, we would like to study it also from the standpoint of physical therapy and motion control of human beings.

\section{References}

Aaron M. Dollar, Hugh Herr. ( 2007). Active Orthoses for the Lower-Limbs: Challenges and State of the Art, Proceedings of the 2007 IEEE 10the International Conference on Rehabilitation Robotics, pp.968-977.

Akai H, Jin Y, Kikuchi T, Fukushima K and Furusho J (2008) ,Study on Development of Active-Passive Rehabilitation System for Upper Limbs, "Hybrid-PLEMO", Proceedings of The 7th International Conference on Machine Automation, pp.67-70.

Bampton S.(1979). A guide to the visual examination of pathological gait, Philadelphia, Temple University-Moss Rehabilitation Hospital.

Bashir M.Y. Nouri and Arafat Zaidan. (2006). Conputer control of a powered two degree freedom reciprocating gait orthosis, ISA Transaction, vol.45, No. 2, pp.249-258.

Bohannon, R.W. (1991). Correlation of knee extension force and torque with gait speed in patients with stroke, Physiotherapy Theory and Practice, Vol.7, No.3, pp.185-190.

Bossis, G. (2002). Ed., Proceedings of the eighth International conference on Electrorheological fluids and Magnetorheological Suspensions. World Scientific

Burgar, C. G. ; Lum, P.S. ; Shor, P. C. \& der Loos, H. M. V. (2000). Development of robots for rehabilitation therapy : The palo alto va/ stanford experience, Jurnal of Rehabilitation Reseach and Development, Vol. 37, No.6, 663-673

Cappozzo A.(1984). Gait analysis methodology, Hum. Mov. Sci., vol.3, pp.27-50.

Carlson, J. D. and Jolly, M. R. (2000). MR fluid, foam and elastomer devices, Mechatronics, Vol.10, pp. 555-569.

Charles, S. ; Krebs, H. I. ; Volpe, B. T. ; Lynch, D. \& Hogan, N. (2005). Wrist rehabilitation following stroke:Initial clinical results, Proceedings of the 2005 IEEE 9th International Conference on Rehabilitation Robotics, 13-16 D.A. Lawrence and J.D. Chapel. (1994). "Performance Trade-offs for Hand Controller Design" Proc. of the 1994 IEEE Conference on Robotics and Automation, San Diego, CA, pp. 3211-3216.

D.E.Voss, M.K.Ionta, B.J.Myers, "proprioceptive neuromuscular facilitation, patterns and techniques," Third Edition, Sedgwick Mead.

Demeurisse, G. et al. (1980). Motor evaluation in vascular hemiplegia, Eur, Neurol., Vol.19, 382-389 Fugel-Meyer A. R. et al. (1975). The post-stroke hemiplegic patient1, a method for evaluation of physical perpormance, Scand. J. Rahabil. Med., Vol.7, 1331

Esquenazi A. and Hirai B.(1991). Assessment of gait and orthotic prescription, Phys Med Rehabil Clin North Am, vol.2, pp.473-485.

Fugl-Meyer A. R. et al., (1975), The post-stroke hemiplegic patient1, a method for evaluation of physical performance, Scand. J. Rahabil. Med., vol. 7, 13-31. 
Furusho, J. \& Kikuchi, T. (2006). Collaboration of medical engineering and fluid power (Review paper), Journal of the Japan Fluid Power System Society, Vol.37, No.5, 272276 (In Japanese)

Furusho, J. \& Masubuchi, M. (1987). A theoretically motivated reduced order model for the control of biped locomotion, Trans. ASME, Journal of Dynamic Systems, Measurement and Control, Vol.109, 155-163

Furusho, J. \& Sakaguchi, M. (1999). New actuators using ER fluid and their applications to force display devices in virtual reality and medical treatments, International Journal of Modern Physics B, Vol.13, No.14, 15 \& 16, 2151-2159

Furusho, J. \& Sano, A. (1990). Sensor-based control of a nine-link biped, The International Journal of Robotics Research, Vol.9, No.2, 83-98

Furusho, J. \& Takesue, N. et al. (2004). Development of intelligent prosthetic ankle joint (1st report, development of linear-type MR-fluid brake), Transactions of the Japan Society of Mechanical Engineers (C), Vol.70, No.695, 275-282

Furusho, J. (2001). Mechatronics system using ER fluids (review paper), Journal of Japan Hydraulics and Pneumatic Society, Vol. 32, No .6, 390-395 (In Japanese)

Furusho, J.; Hu, X.; Kikuchi, T.; Nakayama, K.; Yamaguchi, Y.; Li, C.; Shichi, N.; Inoue, A. \& Ryu, U. (2006). Development of a 6-DOF force display system using ER actuator with high-safety, Proceedings of the ACM International Conference on Virtual Reality Continuum and Its Applications 2006 (CD-ROM), 405-408

Furusho, J.; Jin, Y, Oda K, Haraguchi M, Kikuchi,T, Akai H, (2009)A Performance Evaluation Method of a Passive-Type Force Display and Rehabilitation System with Redundant Brakes, Proceedings of The 2009 IEEE 11th International Conference on Rehabilitation Robotics (in press).

Furusho, J.; Kikuchi, T., Tokuda .M.; Kakehashi, T.; Ikeda, K.; Morimoto, S.; Hashimoto,Y.; Tomiyama, H.; Nakagawa, A. \& Akazawa, Y.(2007). Development of Shear Type Compact MR Brake for the Intelligent Ankle-Foot Orthosis and Its Control (Research and Development in NEDO for Practical Application of Human Support Robot), Proceedings of IEEE International Conference on Rehabilitation Robotics.

Furusho, J.; Kikuchi, T.; Oda, K.; Ohyama, Y.; Morita, T.; Shichi, N.; Jin, Y. \& Inoue, A.(2007). A 6-DOF Rehabilitation Support System for Upper Limbs including Wrists "Robotherapist" with Physical Therapy, Proceedings of IEEE International Conference on Rehabilitation Robotics.

Furusho, J.; Koyanagi, K.; Imada, Y.; Fujii, Y.; Nakanishi, K.; Domen, K.; Miyakoshi, K. U. Ryu, S. Takenaka, A, Inoue. (2005). A 3-D Rehabilitation system for Upper Limbs Developed in a 5-year NEDO Project and its Clinical Testing, Proceedings of the 2005 IEEE 9th International Conference on Rehabilitation Robotics , 53-56

Furusho, J.; Koyanagi, K.; Kataoka, J. Ryu, U.; Inoue, A. \& Takenaka, S. (2005). Development of 3-D rehabilitation system for upper limb -1st report: development of mechanism including ER actuators and whole system -, Journal of the Robotics Society of Japan, Vol.23, No.5, 629-636 (In Japanese)

Furusho, J.; Li, C.; Morimoto, S.; Tokuda, M.; Kikuchi, T. \& Hashimoto, Y. (2007). Development of Shear-type MR Brakes and their Application to Ankle-Foot Orthoses, Proceedings of the International Conference on Complex Medical Engineering (CD-ROM), 1283-1287. 
Furusho, J.; Sakaguchi, M.; Takesue, N. \& Koyanagi, K. (2002). Development of ER brake A 6-DOF Rehabilitation System for Upper Limbs "Robotherapist" and Other Rehabilitation Systems with High Safety 39 and its application to passive force display, Journal of Intelligent Material Systems and Structures, Vol. 13, No. 7/8, 425-429

Furusho, J.; Wei, Z. \& Koga, S. (1995). Development of an actuator with low inertia using electro-rheological fluid and its application to virtual reality, Proceeding of the 72nd JSME Spring Annual Meeting, Vol.4, 265-266

Furusho,J, Sakaguchi,M.and Takesue,N. (2002) Basic Study for Development of MuscularStrength Estimation and Training System Using ER Brake, Journal of Robotics Society of Japan,Vol.20,No.1,pp.77-84

Furusho,J., Ozaw,T. \& Kikuchi,T (2009). Study and Development of Quasi-3D Rehabilitation System for Upper Limbs "PLEMO-P3", Proc. of 46th Annual Meeting of the Japanese Association of Rehabilitation Medicine (in Press).

Gihodo Shuppan. (1992). The handbook of the characteristics value and equation on human engineering , pp.128-130,(in Japanese).

H. Davis and W. Book. (1997). "Torque control of a redundantly actuated passive type force manipulator," Proceeding of American Control Conference, pp.959-963.

Hill A.V. (1939). The heat of shortening and the dynamic constants of muscle. Proc. Roy. Soc. B. 126, pp.136-195.

Inman V., Ralston H. and Todd F.(1981). Human walking, Baltimore, Williams \& Wilkins.

Ishikawa, T. (2000). Basic Study on the Development of a Rehabilitation Training System, Master's Thesis of Osaka Univesity.

ISO10218 (1992). Manipulating industrial robots-safty.

Jin Y, Kikuchi T, Fukushima K, Akai H, Furusho J (2008), Quasi-3DOF Active-Passive Hybrid Rehabilitation System for Upper Limbs "Hybrid-PLEMO", The Journal of the Japan Society of Mechanical Engineers, Vol.74, No.745, pp.2099-2106 (in Japanese).

Jin Y, Kikuchi T, Furusho J, Akai H (2009), A Basic Study on a Passive-Type Force Display System with Redundant Brakes (Performance Evaluation Methods and Force Display in Collision), The Journal of the Japan Fluid Power System Society (in Japanese) (in press).

Jinung An and Dong-Soo Kwon. (2002). Haptic Experimentation on a Hybrid Active/Passive Force Feedback Device, Proceedings of the 2002 IEEE International Conference on Robotics Automation,pp4218-4222

Joaquin A. Blaya and Hugh Herr. ( 2004). Adaptive Control of a Variable-Impedance AnkleFoot Orthosis to Assist Drop-Foot Gait, IEEE Transactions on Neural Systems and Rehabilitation Engineering, vol.12, No.1, pp.24-31.

K. Koyanagi, T. Morita and J. Furusho. (2005). "Basic Algorithm of Controlling Passive Force Display System with Redundant Brakes", Proceedings of the 2005 IEEE International Conference on Robotics \& Automation, pp.1767-1772.

Keith E. Gordon and Daniel P. Ferris. (2007). Learning to walk with a robotic ankle exoskeleton, Journal of Biomechanics, vol.40, pp.2636-2644.

Kelli, E. and Baltzopoulos, V. (1996). Agonist and antagonist moment and EMB-angle relationship during isokinetic eccentric and concentric exercise, Isokinetics and Exercise Science, Vol.6, No.2, pp.79-87. 
Kikuchi, T. Furusho, J., and Oda K. (2003). Development of Isokinetic Exercise Machine Using ER Brake, Proceedings of the 2003 IEEE International Conference on Robotics \& Automation, pp.214-219.

Kikuchi, T., Furusho, J., Yamaguchi, Y. and Kimura, S.(2006). Design of the highperformance MR brake and its characteristics, Proceedings of the 10th International Conference on ER Fluids and MR Suspensions, p667-673.

Kikuchi, T.; Furusho, J.; Jin, Y.; Hu, X.; Fukushima, K. \& Inoue, A. (2007). Development of the quasi-3-DOF rehabilitation system for upper limbs, "PLEMO", The Japanese Journal for Medical Virtual Reality, Vol.5, No.1, 24-31

Krebs, H. I.; Volpe, B. T.; Aisen, M. L. \& Hogan, N. (2000). Increasing productivity and quality of care : Robot-aided neuro rehabilitation, Jurnal of Rehabilitation Research and Development, Vol. 37, No.6, 639-652

Li C. \& Furusho, J. et al. (2006) Developement of intelligent prosthetic ankle joint (2nd report, development of the 1st prototype with intelligent prosthetic ankle joint), Transactions of the Japan Society of Mechanical Engineers (C), Vol.72, No.714, 493498

Li, C.; Miwa, T.; Furusho, J.; Morimoto, S.; Koyanagi, K.; Nakagawa, A.; Akazawa, Y. \& Hashimoto, Y. (2006). Research and developement of the intelligently-controlled prosthetic ankle joint, Proceedings of 2006 IEEE International Conference on Mechatronics and Automation, 1114-1119

Miyakoshi K, Domen K, Koyama T, Furusho J, and Koyanagi K (2006), The effect of Robotaided training on motor recovery following stroke, The Japanese Journal of Rehabilitation Medicine, vol.43, No.6, 47-352.

Oda K, Isozumi S, Ohyama Y, Tamida K, Kikuchi T, Furusho J(2009), Development of Isokinetic and Iso-contractile Exercise Machine "MEM-MRB" Using MR Brake, Proceedings of The 2009 IEEE 11th International Conference on Rehabilitation Robotics (in press).

Redford JB. (1984). "Orthoses," In: Basmajian JV., and Kirby RL., eds., Medical rehabilitation, Baltimore, Williams \& Wilkins, pp.101.

Sakaguchi, M.; Furusho, J. \& Genda, E. (1999). Basic study in rehabilitation training system using ER actuators, Proceeding of 1999 IEEE International Conference on Systems, Man, and Cybernetics, 135-140 (in Japanese)

T. Flash and N. Hogan (1985). "The Coordination of Arm Movements: An Experimentally Confirmed Mathematical Model", the Journal of Neurosciecne, Vol.5, No.7, pp.1688-1703.

Takesue, N., Furusho, J. and Kiyota, Y.(2004). Fast Response MR-Fluid Actuator, JSME International Journal, Series C, Vol.47, No.3, pp.783-791.

Verrill, D., Shoup, E., McElveen, G., Witt, K. and Bergey, D.(1992).Resistive Exercise Training in Cardiac Patients (Review Article), Sports Medicine, Vol.13, No.3, pp.171-193. 


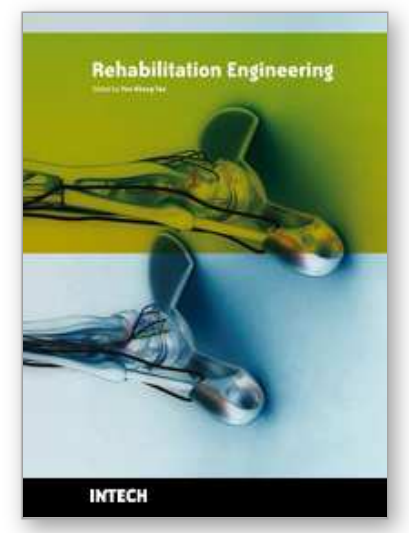

\author{
Rehabilitation Engineering \\ Edited by Tan Yen Kheng
}

ISBN 978-953-307-023-0

Hard cover, 288 pages

Publisher InTech

Published online 01, December, 2009

Published in print edition December, 2009

Population ageing has major consequences and implications in all areas of our daily life as well as other important aspects, such as economic growth, savings, investment and consumption, labour markets, pensions, property and care from one generation to another. Additionally, health and related care, family composition and life-style, housing and migration are also affected. Given the rapid increase in the aging of the population and the further increase that is expected in the coming years, an important problem that has to be faced is the corresponding increase in chronic illness, disabilities, and loss of functional independence endemic to the elderly (WHO 2008). For this reason, novel methods of rehabilitation and care management are urgently needed. This book covers many rehabilitation support systems and robots developed for upper limbs, lower limbs as well as visually impaired condition. Other than upper limbs, the lower limb research works are also discussed like motorized foot rest for electric powered wheelchair and standing assistance device.

\title{
How to reference
}

In order to correctly reference this scholarly work, feel free to copy and paste the following:

Junji Furusho and Ying Jin (2009). A 6-DOF Rehabilitation System for Upper Limbs "Robotherapist"and Other Rehabilitation Systems with High Safety, Rehabilitation Engineering, Tan Yen Kheng (Ed.), ISBN: 978-953307-023-0, InTech, Available from: http://www.intechopen.com/books/rehabilitation-engineering/a-6-dofrehabilitation-system-for-upper-limbs-robotherapist-and-other-rehabilitation-systems-with-hi

\section{INTECH}

open science / open minds

\author{
InTech Europe \\ University Campus STeP Ri \\ Slavka Krautzeka 83/A \\ 51000 Rijeka, Croatia \\ Phone: +385 (51) 770447 \\ Fax: +385 (51) 686166 \\ www.intechopen.com
}

\author{
InTech China \\ Unit 405, Office Block, Hotel Equatorial Shanghai \\ No.65, Yan An Road (West), Shanghai, 200040, China \\ 中国上海市延安西路65号上海国际贵都大饭店办公楼 405 单元 \\ Phone: +86-21-62489820 \\ Fax: +86-21-62489821
}


(C) 2009 The Author(s). Licensee IntechOpen. This chapter is distributed under the terms of the Creative Commons Attribution-NonCommercial-ShareAlike-3.0 License, which permits use, distribution and reproduction for non-commercial purposes, provided the original is properly cited and derivative works building on this content are distributed under the same license. 